\title{
Airborne observation during KORUS-AQ show aerosol optical depth are more spatially self-consistent than aerosol intensive properties
}

5 Samuel E. LeBlanc ${ }^{1,2}$, Michal Segal-Rozenhaimer ${ }^{1,2,3}$, Jens Redemann ${ }^{4}$, Connor Flynn ${ }^{4}$, Roy R. Johnson², Stephen E. Dunagan², Robert Dahlgren², Jhoon Kim ${ }^{5,10}$, Myungje Choi $^{5,6,7}$, Arlindo da Silva ${ }^{7}$, Patricia Castellanos ${ }^{7}$, Qian Tan ${ }^{1,2}$, Luke Ziemba ${ }^{8}$, K. Lee Thornhill 8,9 , Meloë Kacenelenbogen²

${ }^{1}$ Bay Area Environmental Research Institute ${ }^{2}$ NASA Ames Research Center ${ }^{3}$ Department of Geophysics, Porter School of the Environment and Earth Sciences, Tel-Aviv University ${ }^{4}$ University of Oklahoma, School of Meteorology

${ }^{5}$ Yonsei University 6 University of Maryland Baltimore County

$15 \quad{ }^{7}$ NASA Goddard Space Flight Center ${ }^{8}$ NASA Langley Research Center ${ }^{9}$ Science Systems and Application Inc. ${ }^{10}$ Particulate Matter Research Institute, Samsung Advanced Institute of Technology (SAIT)

Correspondence to: Samuel E. LeBlanc (samuel.leblanc@nasa.gov)

\section{Abstract}

Aerosol particles can be emitted, transported, removed, or transformed, leading to aerosol variability at scales impacting the climate (days to years and over hundreds of kilometers) or the air quality (hours to days and from meters to hundreds of kilometers). We present the temporal and spatial scales of changes in AOD (Aerosol Optical Depth), and aerosol size (using Angstrom Exponent; AE, and Fine-Mode-Fraction; FMF) over Korea during the 2016 KORUS-AQ (KORea-US Air Quality) atmospheric experiment. We use measurements and retrievals of aerosol optical properties from airborne instruments for remote sensing (4STAR; Spectrometers for Sky-Scanning Sun Tracking Atmospheric Research) and in situ (LARGE; NASA Langley Aerosol Research Group Experiment) on board the NASA DC-8, geostationary satellite (GOCl; Geostationary Ocean Color Imager; Yonsei aerosol retrieval (YAER) version 2) and reanalysis (MERRA-2; Modern-Era Retrospective Analysis for Research and Applications, version 2). Measurements from 4STAR when flying below $500 \mathrm{~m}$, show an average AOD at 501 $\mathrm{nm}$ of 0.43 and an average $\mathrm{AE}$ of 1.15 with large standard deviation ( 0.32 and 0.26 for $A O D$ and $A E$ respectively) likely due to mixing of different aerosol types (fine and 
coarse mode). The majority of AODs due to fine mode aerosol is observed at altitudes lower than $2 \mathrm{~km}$. Even though there are large variations, for 18 out of the 20 flight days, the column AOD measurements by 4STAR along the NASA DC-8 flight trajectories matches the south-Korean regional average derived from $\mathrm{GOCl}$.

We also observed that, contrary to prevalent understanding, $A E$ and FMF are more spatially variable than AOD during KORUS-AQ, even when accounting for potential sampling biases by using Monte Carlo resampling. Averaging between measurements and model for the entire KORUS-AQ period, a reduction in correlation by $15 \%$ is $65.0 \mathrm{~km}$ for AOD and shorter at $22.7 \mathrm{~km}$ for AE. While there are observational and model differences, the predominant factor influencing spatial-temporal homogeneity is the meteorological period. High spatio-temporal variability occur during the dynamic period (25-31 May), and low spatio-temporal variability occur during blocking Rex pattern (0107 June). The changes in spatial variability scales between AOD and FMF/AE, while interrelated, indicate that microphysical processes that impact mostly the dominant aerosol size, like aerosol particle formation, growth, and coagulation, vary at shorter scales than the aerosol concentration processes that mostly impact AOD, like aerosol emission, transport, and removal.

\section{Plain Language (Short) Summary}

Airborne observations of atmospheric particles and pollution over Korea during a field campaign in May-June 2016 showed that the smallest atmospheric particles are present in the lowest $2 \mathrm{~km}$ of the atmosphere. The aerosol size is less repeatable over distances than their optical thickness. We show this with remote sensing (4STAR), insitu (LARGE) observations, satellite measurements (GOCI), and modeled properties (MERRA-2), and it is contrary to current understanding.

\section{Keywords}

KORUS-AQ; Aerosol Optical Depth; airborne observations; aerosol intensive properties 


\section{Introduction}

Aerosol interactions with light are governed by their intensive and extensive properties (Rajesh and Ramachandran, 2020). Intensive properties represent the aerosol optical properties that do not scale with aerosol concentration or mass, such as angstrom exponent ( $A E)$, fine mode fraction (FMF), single scattering albedo, asymmetry parameter, index of refraction, and hemispheric backscatter fraction. These intensive properties depend on the intrinsic properties of the aerosol; its size, shape and composition (Russell et al., 2010). Conversely, extensive properties such as aerosol optical depth (AOD), extinction, scattering, and absorption are predominantly dependent on the amount of aerosol particles present.

The spatio-temporal scales at which the extensive and intensive properties vary are directly linked to the processes governing the emission, transport, removal, and transformation of the aerosol particles. The modelled aerosol lifetime or rate of change is directly represented by these aerosol processes (e.g., Tsigardis et al., 2014; Hodzic et al., 2016; Saide et al., 2020), however, assessing the aerosol processes from atmospheric observations alone require consistent observations of multiple aerosol intensive and extensive properties. Anderson et al. (2003) described the use of aerosol's variability across spatial and time scales, as observed by multiple measurements, to better resolve the integration needed to calculate aerosol radiative forcing of climate, thus reducing its uncertainties. The high aerosol variability across scales shorter than $200 \mathrm{~km}$ was attributed to the aerosol processes such as patchy sources, sinks, and short residence time of tropospheric particles. Shinozuka and Redemann (2011) showcased the difference between high aerosol spatio-temporal variability in the Arctic, with freshly emitted biomass burning plumes from boreal forest fire, and low variability for aerosol long-distance transport near the north pole. Targino et al. (2005) presented cases where the aerosol extensive properties (scattering and absorption coefficients) change at scales smaller than the airmass/mesoscale, compared to intensive properties ( $\mathrm{AE}$ and single scattering albedo) that varied much less.

Understanding the variability of aerosols helps reduce uncertainties in aerosol direct radiative effect by quantifying the errors due to interpolating between sparse aerosol observations sites or modeled pixels. Since the aerosol direct radiative effect is an integral over time and space, variations of aerosol impact its derivation, e.g., integrating the radiative effect over $20 \mathrm{~km}$ for long distance aerosol transport in the Canadian Arctic will only be subject to variations of $2 \%$, while integrating over aerosol from boreal forest fires will give 19\% variations (Shinozuka and Redemann, 2011; Kacenelenbogen et al., 2019). This impact can be important not only due to aerosol variability but also due to changes in underlying surface, like when aerosol overly clouds or varying surface (from sea to land). Min and Zhang (2014) presented potential biases in the direct aerosol radiative effect by up $10 \%$ when using mean gridded values as input, which are susceptible to subgrid horizontal heterogeneity. Defining the length scales at which aerosol variability impacts quantification of the direct aerosol radiative effect is important for reducing uncertainties in the upcoming observational capabilities afforded by the AOS (Atmosphere Observing System). 
Similarly, quantifying the scale of aerosol variability can reduce errors in modelling atmospheric particles impacting air quality where observations are sparse and horizontal variations of these small aerosol particles often occur at scales shorter than the spacing between observations. Additionally, constraining the scales at which natural variations occur is necessary to quantify the minimum collocation criteria when combining multiple observations and model platforms from AOS to upcoming field campaigns. This is similar to the question "How Long Is Too Long?" described by Sayer $(2020)$ or for validation plan such as the upcoming GEMS satellite (Park et al., 2020b). In addition, retrieval biases like small scale cloud contamination in AOD pixel

110 retrievals from MODIS can be identified when comparing the expected natural variation as measured by 4STAR's predecessor (AATS-14; NASA Ames Airborne Tracking Sunphotometer) to the higher spatial variation retrieved by MODIS for the same matched scenes (Redemann et al., 2006). Here we investigate the accepted hypothesis that intensive aerosol properties are more homogeneous over larger length-scales than their extensive counterpart, as exemplified

115 by a more horizontally homogeneous PM2.5 and its chemical composition than AOD in the southeast U.S. (Kaku et al., 2018). We do this for aerosol measurements over the Korean Peninsula and its surrounding seas, where the aerosol type is dominantly mixed (urbanindustrial, maritime, continental, sub-continental, biomass burning, and even some dust; Lee et al., 2018) due to multiple aerosol sources and transformation processes, contrary to other 120 studies. This study has the potential to provide insight in air quality prediction, monitoring, and ultimately control.

The KORea-US Air Quality (KORUS-AQ; Crawford et al., 2021; Choi et al., 2019; Peterson et al., 2019) field study measured atmospheric composition over the Korean peninsula and surrounding waters from May to July 2016. During KORUS-AQ, the atmosphere was sampled by multiple airborne and ground-based remote sensing and in-situ measurements. Central to this paper is the airborne sunphotometer, 4STAR (Spectrometers for Sky-Scanning SunTracking Atmospheric Research; Dunagan et al., 2013). 4STAR's main measurement is the spectral AOD representing the column above the aircraft. The following section summarizes the KORUS-AQ campaign, the 4STAR instrument, the space-borne sensor, and the model used in this study. The methodology of defining length-scale consistency among different properties is presented in section 3, major findings and discussion in section 4, and conclusion in section 5. The appendixes provide some 4STAR measurement corrections, and comparison of AOD measurements during KORUS-AQ between 4STAR, GOCI, and MERRA-2.

\section{Data Sources and Instruments}

\section{$135 \quad$ 2.1 Korea - United States Air Quality experiment (KORUS-AQ)}

As a result of the dramatic increase in economic and energy production in East Asia since 2010, there has been a significant increase in fine particle and ozone pollution emission (Crawford et al., 2021). The air quality has been impacted in the recent decade, particularly in the Seoul metropolitan area, with a population of $\sim 25$ million. A better understanding of the sources and

140 evolution of the aerosol particles in the region motivated a large-scale measurement campaign. The KORUS-AQ field study (Crawford et al., 2021), from May to June 2016, oversaw the deployment of the NASA DC-8 airborne research laboratory. KORUS-AQ was a joint effort by National Institute of Environmental Research of South Korea and NASA, and oversaw the 
deployment of three research aircraft, extensive ground-based networks and three ships to observe and quantify the air quality in south Korea due to local and transported sources. The NASA DC-8 flew a total of 20 research flights over the South Korean peninsula and surrounding waters (see Fig. 1). Portions of each research flight were conducted while keeping a near constant altitude (level legs) to quantify both the emission sources and the upwind/downwind variability of aerosol properties. These level legs that occurred mostly in the common corridors for air traffic and above research sites and common sources, enabled us to bound the spatial variability of aerosol properties (AOD, $A E$, and $F M F)$ and thus giving a restriction of the combined aerosol microphysical processes and aerosol sources and sinks. These level legs are illustrated in Fig. 1, and were identified through a running standard deviation of less than 5 meters in altitude for each 20 second segment.

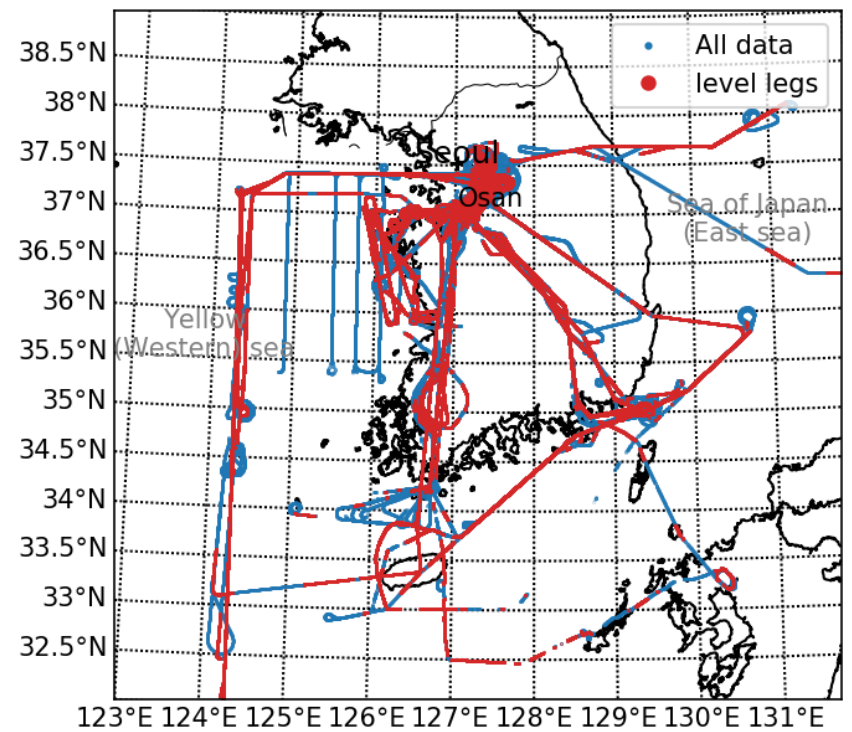

Figure 1 - Map of NASA DC-8 flight paths during KORUS-AQ (blue), with the level (horizontal) legs with high-quality and cloud-free 4STAR data (red).

During KORUS-AQ, the atmospheric conditions were divided into four main periods presented in Table 1 (summarized from Peterson et al., 2019).

\begin{tabular}{l|l|l|l} 
& Date range & Short name & Description \\
\hline $\mathbf{1}$ & $01-16$ May & dynamic & dynamic meteorology and complex aerosol vertical profiles \\
\hline $\mathbf{2}$ & $17-22$ May & stagnation & stagnation under a persistent anticyclone \\
\hline $\mathbf{3}$ & $25-31$ May & $\begin{array}{l}\text { extreme } \\
\text { pollution } \\
\text { blocking }\end{array}$ & $\begin{array}{l}\text { dynamic meteorology, low-level transport, and haze } \\
\text { development with extreme pollution } \\
\text { blocking pattern with a high-pressure ridge precluding any } \\
\text { significant changes in synoptic meteorology }\end{array}$ \\
\hline $\mathbf{4}$ & 01-07 June & signe
\end{tabular}

160 Table 1 - Description and time ranges of the four main meteorological periods during KORUS$A Q$. 
Under each of these four time periods (dynamic, stagnation, extreme pollution, and blocking), the atmospheric dynamics and weather patterns have either promoted local production of aerosols (haze development in period 2 and 4, and mostly local sources in period 3) (Jordan et al., 2020) or brought in some long range transport of aerosols (dust transport in period 1, lowlevel pollution transport in period 2) from neighboring land and sea areas such as the Gobi desert, Shanghai, and Beijing (Peterson et al., 2019; Choi et al., 2019).

\subsection{Spectrometers for Sky-Scanning Sun-Tracking Atmospheric Research (4STAR)}

4STAR combines airborne sun tracking and sky scanning with diffraction spectroscopy and was integrated in the NASA DC-8 in the zenith port. This airborne sun tracker and sky radiometer has multiple operating modes, which are selected by the operator depending on the sky conditions above the aircraft. 4STAR observes spectral AOD (see LeBlanc et al., 2020), aerosol properties (e.g., single scattering albedo, scattering phase function, aerosol size distribution, aerosol refractive index) derived from skylight measurements following the AERONET retrievals (see Pistone et al., 2019), column trace gas density (e.g., water vapor, $\mathrm{O}_{3}, \mathrm{NO}_{2}$ ) using spectroscopic methods (see Segal-Rosenheimer et al., 2014), or cloud properties (cloud optical depth, effective radius, and thermodynamic phase) from transmitted light (LeBlanc et al., 2015, Smith et al., 2017). Here we focus on 4STAR's measurements of direct solar irradiance, AOD

180 and derived products using its sun-tracking operating mode. 4STAR incorporates a modular sun-tracking/sky-scanning optical head with fiber optic signal transmission to rack mounted spectrometers with spectral resolution ranges from $0.5-1 \mathrm{~nm}$ from $350 \mathrm{~nm}$ to $1000 \mathrm{~nm}$ and 3-6 $\mathrm{nm}$ from $1000 \mathrm{~nm}$ to $1750 \mathrm{~nm}$. The uncertainty of the AOD during KORUS-AQ is dependent on wavelength, solar angles, and varying corrections, but averages to 0.032 at $501 \mathrm{~nm}(0.033$ at

$185452 \mathrm{~nm}$ to 0.027 at $1627 \mathrm{~nm}$ ). This uncertainty includes corrections due to the deposition of material on the instrument window, fiber-optic rotating joint, gas phase absorption, and spectrometer non-linear correction, averaging to an uncertainty in AOD at $501 \mathrm{~nm}$ of 0.014 , $0.0018,0.0006$, and 0.0005 respectively (described in appendix $A$ ), and the variability observed during the calibrations at Mauna Loa Observatory $(0.67 \%$ standard deviation derived from six

190 Langley-extrapolations, similarly method to Shinozuka et al., 2013 and LeBlanc et al., 2020). Recent advances in the fiber optic light path on 4STAR is also described in appendix A, which resulted in higher throughput and consistency in between calibrations (increasing number of viable Langley calibration from two (during TCAP; Shinozuka et al., 2013) to six) and removed the need for a temperature correction. Processing procedures and codes of the 4STAR raw measurements of solar direct beam into quality-assured AOD are presented by the 4STAR Team et al. (2020).

\subsection{Satellite-based remote sensing of AOD and Angstrom Exponent (GOCI)}

The Geostationary Ocean Color Imager (GOCl), Yonsei aerosol retrieval (YAER) version 2 (Choi et al., 2018) provides a geostationary view of aerosol evolution over the Korean

200 peninsula. This algorithm uses the reflectances measured by $\mathrm{GOCl}$ at eight spectral channels and retrieves hourly AOD at $550 \mathrm{~nm}$ and FMF (Fine mode fraction) over ocean and land. The native $0.5 \mathrm{~km} \times 0.5 \mathrm{~km}$ resolution of $\mathrm{GOCl}$ is masked for clouds, inland waters, and highly turbid waters, and is aggregated to an AOD product with $6 \mathrm{~km} \times 6 \mathrm{~km}$ resolution, by using the mean 
AOD from three aerosol models among total 27 models having best fits between calculated and measured spectral top-of-atmosphere reflectance. The GOCI YAER retrieved AOD is matched to the closest 4STAR observation in time and space along the DC-8 flight path during KORUS$A Q$. The co-location criteria is a maximum of 30 minutes between the satellite and airborne observations, and a maximum distance of $3 \mathrm{~km}$. The expected deviation of AOD during this 30 minute lag is lower than 0.06 , as identified by the variogram analysis of ground-based

210 sunphotometers (Sayer, 2020), and confirmed in Korea at a few AERONET stations (Park et al., 2020b). Detailed GOCl aerosol retrieval algorithm, AOD features, and evaluation during the campaign are described in Choi et al. (2019).

\subsection{MERRA-2 aerosol modelling and computation of AOD}

The emission, evolution, transport, and removal of aerosols are represented by a reanalysis

215 system, NASA's Modern-Era Retrospective Analysis for Research and Applications, version 2 (MERRA-2; Buchard et al., 2017; Randles et al., 2017). For understanding the vertically integrated $A O D$, and $A E$ intensive properties, we used the hourly resolved aerosol diagnostics with a spatial resolution of $0.5^{\circ} \times 0.625^{\circ}$ (roughly $59 \mathrm{~km}$ between two pixels) (GMAO 2015). In MERRA-2, aerosols are simulated by GEOS model driven by assimilated meteorology fields and assimilates AOD from MODIS, MISR, AVHRR, and AErosol RObotic NETwork (AERONET; Holben et al., 1998) to build a four-dimensional gridded model representation of the real world's sparse observations.

The reanalysis $A O D$ and $A E$ values are interpolated in time and space (4D) along the $D C-8$ flight trajectory from samples of a global analysis with a spatial resolution of 0.3125 -degree

225 longitude by 0.25 -degree latitude at a temporal resolution of 3 hour (Collow, et al., 2020). This gives a maximum temporal difference of 90 minutes and a maximum distance difference of approximately $12 \mathrm{~km}$ between airborne observations and reanalysis grid point. MERRA-2's total AOD include five species of aerosol: dust, sea salt, organic carbon, black carbon, and sulfates. The size distributions of sulfates, organic, and black carbon aerosols are all modeled as

230 lognormal distributions. The mode of the lognormal distribution for the dry aerosol is $0.0695 \mu \mathrm{m}$, $0.0212 \mu \mathrm{m}$, and $0.0188 \mu \mathrm{m}$ for sulfate, organic carbon, and black carbon, respectively. The minimum and maximum dry particle radii $(R)$ are $0.005 \mu \mathrm{m}$ and $0.3 \mu \mathrm{m}$. The size distributions for sulfate and the hydrophilic portions of organic and black carbon change with relative humidity according to a growth factor (GF) taken from the Global Aerosol Data Set (GADS;

235 Köpke et al. 1997). The computation of the aerosol size within this model is achieved through combining the dry aerosol size with the GF. For some $\mathrm{RH}$ equal to $n$ mode of the lognormal distribution $\left(R_{M}^{n}\right)$ and the maximum radius $\left(R_{\text {Max }}^{n}\right)$ is given by:

$R_{M}^{n}=G F^{n} R_{M}^{d r y}$

$R_{\text {Max }}^{n}=G F^{n} R_{\text {Max }}^{\text {dry }}$

240 The dusts and sea salt aerosols have their size defined through a five-bin system, ranging from $0.1 \mu \mathrm{m}$ to $10 \mu \mathrm{m}$ for dust, and $0.03 \mu \mathrm{m}$ to $10 \mu \mathrm{m}$ for sea salt. Dust is modeled as hydrophobic, while sea salt is hydrophilic. The particle size distribution in each sea salt bin is described by equation 2 in Gong (2003). Particle growth as function of RH is from Gong et al. (1997) (see equation 3 and Table 2). The size of each sea salt bin changes as the particles grows. 
245 While not strictly super-micron aerosol sizes, majority of sea salt and dust are considered here as corresponding to the optically derived coarse mode aerosols, and the sulfates, organic, and black carbon aerosol are considered as part of the optically defined fine mode aerosol. The modeled FMF is taken to be the fraction of total AOD that comes from sulfate, organic carbon, and black carbon.

2.5 In situ airborne aerosol extinction measurements from LARGE (NASA Langley Aerosol Research Group Experiment)

In situ optical aerosol measurements from the NASA DC-8 were obtained by LARGE (NASA Langley Aerosol Research Group Experiment; Ziemba et al., 2013) using a combination of TSI3563 nephelometers for scattering coefficients, Radiance Research 3-wavelength PSAP

255 (Particle Soot Absorption Photometer) for absorption coefficients (with wavelength-dependent corrections from Virkkula, 2010), and the impact on scattering by hygroscopic growth using nephelometers measuring aerosols at dry $(<20 \% \mathrm{RH})$ and humid $(80 \% \mathrm{RH})$ conditions. Scattering coefficients were measured at 450,550 , and $700 \mathrm{~nm}$ and absorption coefficients at 470,532 , and $660 \mathrm{~nm}$. The aerosols are brought into the aircraft for observation via a shrouded

260 solid diffuser inlet which has a cutoff at $5 \mu \mathrm{m}$ dry aerodynamic diameter (McNaughton et al., 2007). The total ambient aerosol scattering coefficient and AE is calculated by correcting dry scattering measurements to ambient relative humidity using a gamma relationship and measured hygroscopicity (Ziemba et al., 2013). Total ambient extinction coefficients are the sum of ambient scattering and dry absorption coefficients. These measurements are sampled at 1

$265 \mathrm{~Hz}$, with an effective distance between sample points of roughly $130 \mathrm{~m}$, and reported at standard temperature and pressure $(273 \mathrm{~K}$ and $1013 \mathrm{mb})$ for quantifying the variability over spatial and temporal domain, even at different altitudes. We use here the total extinction coefficient at $532 \mathrm{~nm}$ and the AE calculated from $550 \mathrm{~nm}$ to $700 \mathrm{~nm}$.

These in situ measurements of the aerosol optical properties represent the aerosol environment at the DC-8 flight altitude, unlike the column observations by the 4STAR and $\mathrm{GOCl}$, and as reported by MERRA-2. Additionally, the column measurements (AOD, AE, and FMF) are derived from optical remote sensing, which is sensitive to aerosol particles over a broad range of sizes at ambient conditions (Hou et al. 2020), while the in situ observations have lower sensitivity to particles larger than $5 \mu \mathrm{m}$ in aerodynamic diameter, owing to the inlet efficiency.

\section{Methodology}

The AOD, AE and FMF observed and modelled during KORUS-AQ are compared to each other first by setting a common time base for comparison. Here we use the AOD observations aboard the NASA DC-8, which has the finest spatial and temporal resolution of all data sources used in this study. Each observation of AOD spectra by 4STAR along the flight path is matched to the nearest LARGE in situ observation, nearest satellite retrieval pixel (GOCI), and to the 4D interpolation of the model reanalysis (MERRA-2). Only the level legs are used here to build this collocated dataset (see Fig. 1). This combined collocated dataset is used to investigate the spatial distribution, spatial variation and representative nature of the AOD, AE and FMF during KORUS-AQ. 


\subsection{Autocorrelation distance}

To identify the distance at which one measurement can be best represented by itself, or to what distance an aerosol property is consistent, we use the autocorrelation metric, as popularized by Anderson et al. (2003), and used by Redemann et al. (2006) and Shinozuka and Redemann (2011). The formulation from eq. 5 by Shinozuka and Redemann (2011) is used here (Eq. 3). Autocorrelation is the correlation coefficient among all data pairs $x_{j}$ and $x_{j+k}$ within a set that exists at a separation, or lag, of $k$. That is,

$r=\frac{\sum_{j}^{N}\left[\left(x_{j}-m_{+k}\right)\left(x_{j+k}-m_{-k}\right)\right]}{(N-1) s t d_{+k} s t d_{-k}}$

where $\mathrm{k}$ indicates the spatial lag (or distance), $\mathrm{m}_{+\mathrm{k}}$ and $\mathrm{std}_{+\mathrm{k}}$ denote the mean and standard deviation respectively, of all data points that are located a distance of $+\mathrm{k}$ away from another data point, and $\mathrm{m}_{-\mathrm{k}}$ and $\mathrm{std}_{-\mathrm{k}}$ are the corresponding quantities for data points located a distance of $-k$ away from another data point. Thus, one can reproduce the autocorrelation at various distances from each sample within a set, here understood as a flight leg.

To relate the autocorrelation distance of samples to the greater physical characteristics of the aerosol itself, a measure of the sampling bias can be estimated. This is done similarly to

300 Shinozuka and Redemann (2011), where a Monte Carlo subsampling of the dataset is chosen, and the standard deviation of the autocorrelation distances is calculated. We used a randomly chosen portion (30\%) of all legs to calculate the autocorrelation distances, which were iterated 50 times to calculate the standard deviation at each distance interval. We also allow each discretized bin, or lag distance $\mathrm{k}$, to be within $20 \%$ of the actual separation distance, effectively

305 making the width of the bin $20 \%$, thereby increasing the data set for calculation. As example, the lag distance $\mathrm{k}$ of $1.0 \mathrm{~km}$ encompasses all points within a segment that are separated by a distance from $0.8 \mathrm{~km}$ to $1.2 \mathrm{~km}$. To remove influence of instrumental noise the shortest autocorrelation bins were ignored.

\subsection{Spectral deconvolution of AOD for obtaining fine mode fraction and relation to Angstrom Exponent}

Inferring particle size information from spectral AOD has been widely demonstrated (O'Neill et al., 2003; O'Neill et al., 2008; Eck et al., 2010). Schuster et al. (2006) points out that for a bimodal distribution, AE may reflect particle size (especially the short wavelengths) or fine mode fraction (reflected more in AE at longer wavelengths). The larger aerosol particles have a flatter

315 spectral shape, and greater impact on extinction at longer wavelengths than small aerosol particles compared to a steeper spectral response in AOD for a similar mid-visible AOD.

Generally, this produces low AE (roughly below 1) when the aerosol optical depth is dominated by the larger aerosol particles, and conversely high AE (roughly greater than 1) for the column dominated by smaller particles. However, when considering changes in not only the size but 320 also chemical composition, low AE (but still mostly above 1) has been observed for fine mode dominant aerosol that are humidified in the Korean Summer (Koo et al., 2021). Koo et al. (2021) describe one of the downfalls of using solely $A E$ for quantifying the fraction of aerosol optical depth that is dominated by fine particles (FMF), and also illustrates the impact of different wavelength ranges used in evaluating $A E$, notably caused by curvature in the spectral $A O D$ 
325 (other examples of variance in AE depending on the range of wavelengths used are presented by LeBlanc et al., 2020 and by Eck et al., 1999). Curvature in spectral AOD can also be caused by the relative proportions of the fine and coarse mode aerosols or the FMF (Eck et al., 1999, Yoon et al., 2012). While AE does relate generally to aerosol size, it is a proxy for FMF. The AOD spectral curvature information, with the assumption that coarse mode aerosol consistently result in low AE, is further exploited in the Spectral Deconvolution Algorithm (SDA; O'Neill, 2003; O'Neill et al., 2001a, 2001b), which is used in AERONET for retrieving FMF.

We apply SDA (O'Neill et al., 2008) on the 4STAR sunphotometer, which unlike AERONET, samples the AOD using spectrometers and allows for wavelength choice. Here the fine mode fraction is still reported at $500 \mathrm{~nm}$, as previously evaluated (e.g., Eck et al., 2010), but we

335 expand the input wavelengths of the AOD spectra to include AOD at 452, 501, 520, 532, 550, $606,620,675,781,865,1020,1040$, and $1064 \mathrm{~nm}$, unlike the 4 typically used from AERONET (O'Neill et al., 2008). While the SDA does not directly evaluate the volumetric fine and coarse mode of aerosol size distribution, this optical equivalent is nearly linearly proportional to the volumetric sizes of the aerosol distribution (e.g., Hou et al., 2020). The AE in Korea is also directly proportional

340 to the FMF except for fine mode aerosol in environments of high relative humidity (above $80 \%$ ) (Koo et al., 2021)

\section{Results and Discussion}

Aerosol distribution over and surrounding the Korean peninsula has contributions and influences from a multitude of varying sources. Recent publications show that the retrieved black and

345 brown carbon aerosol from polarized satellite retrievals over the Korean land mass has distinctly different mass concentration and ratio of black to brown carbon in March through May compared to June through August (Li et al., 2020). Although black and brown carbon aerosol are not the only aerosol types found in this region, their mass concentrations are reported to vary by a factor of 5 over Korea, forming multiple gradients, regional maxima and mimina within

350 the boundaries of the peninsula ( $\mathrm{Li}$ et al., 2020). This type of spatial variance is indicative of multiple processes impacting aerosol in the region. An aerosol process largely impacting the region is the high relative humidity in the summer, which increases the size of the small aerosol particles stemming from pollution and secondary organic formation (Koo et al., 2021).

\subsection{Overview of AOD variability during KORUS-AQ}

355 4STAR measured an average AOD at $501 \mathrm{~nm}$ of 0.36 with a standard deviation of 0.12 , and an average $A E$ of 1.11 with a standard deviation of 0.15 during KORUS-AQ, when flying below 1000 meters.

Aerosol spatial distribution during KORUS-AQ is quantified by spatially binning $\left(0.44^{\circ}\right.$ latitude and $0.33^{\circ}$ longitude) the AOD observations for the entire period and obtaining the mean and standard deviation of each binned AOD (see Fig. 2). The largest AOD averages observed by 4STAR (below $1000 \mathrm{~m}$ altitude) occurred near Seoul, and over the Yellow Sea, on the western coast of Korea. Lower averages were found along the southern coast. The mean AOD at 501 $\mathrm{nm}$ over Seoul during KORUS-AQ is between 0.29 and 0.45 , from the northernmost spatial bin to more southern bins encompassed within Seoul metropolitan area. This range is similar, albeit a bit low compared to the climatologically average observed values from a ground site for May 
and June for the decade $2007-2017$ ( 0.45 and 0.36 respectively; Choi and Ghim, 2021). The regions with the largest variability in $A O D$, as determined by the standard deviation in each of the binned statistics, are observed on the Western Sea, and near Seoul. Directly south of Seoul, where there are large industrial regions, a larger than average standard deviation is also observed. The number of samples aggregated within each spatial bin to build these statistics are represented by the size of the square symbols in Fig. $2 \mathrm{~b}$. The greater Seoul region shows a high number of observations, followed by the sea west of Korea, along the western coast, and over land on the corridor between Seoul and Busan (southeast Korea). Although the remaining regions show some variability, the number of samples are lower than 1000 , with the lowest sampled region coinciding with the smallest average AOD. The standard deviation is only weakly correlated to the number of samples within a bin at a Pearson correlation coefficient of $R^{2}=0.13$, with a higher standard deviation for larger number of samples where every additional 403.2 \pm 99.9 samples there is an additional 0.1 standard deviation in AOD.

The AOD spatial trend which is higher in the northwest, and lower along the southern coast is reproduced in the MERRA-2 reanalysis, for the collocated pixels in time (within three hours) and space to the observations. However, MERRA-2 does not seem to reproduce the same high average AOD over Seoul and the industrial region to the south and tends to overpredict the AOD along the southern coast. Similarly, the geostationary observation by $\mathrm{GOCl}$, show a similar trend of high AOD over the Western Sea and Seoul, with lower values on the Eastern Sea, and south, but the number of high-quality retrievals that are co-located with the NASA DC-8, while flying below $1000 \mathrm{~m}$, are low. 

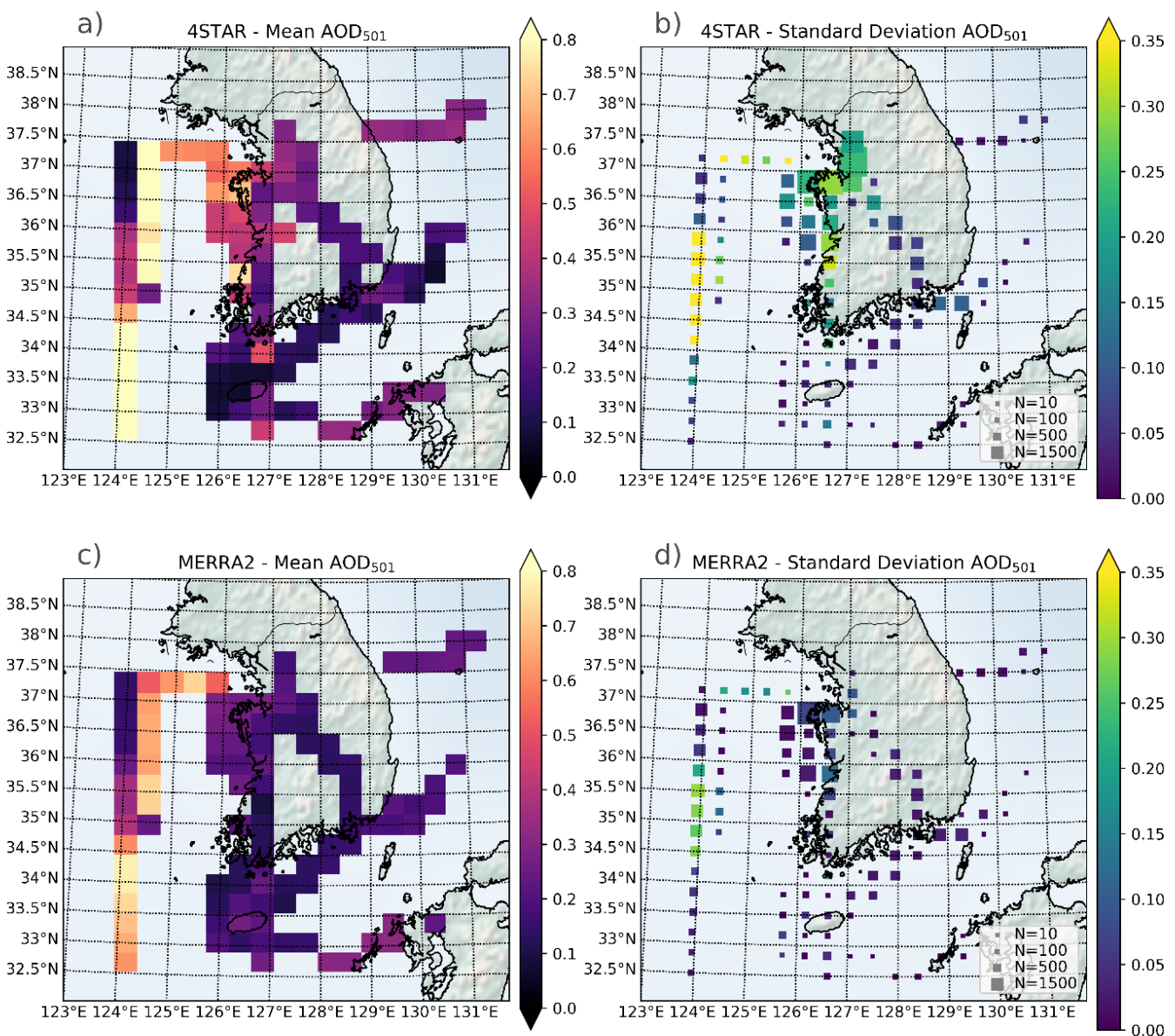

e)

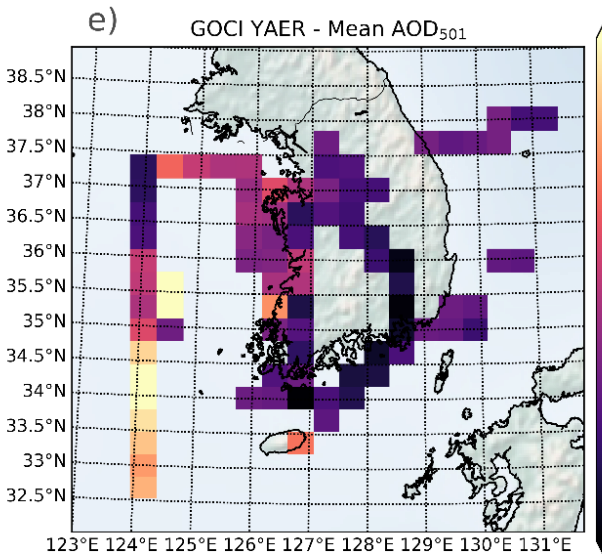

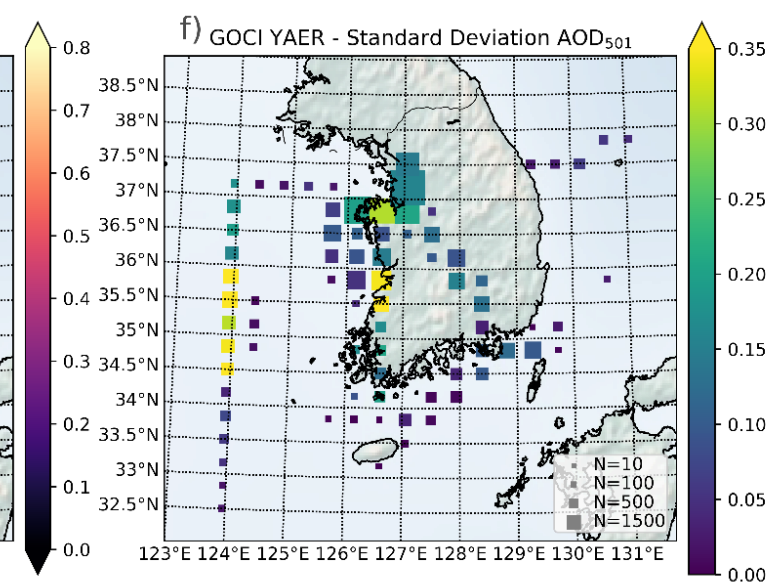

Figure 2 - The spatial distribution binned by $0.44^{\circ}$ latitude and $0.33^{\circ}$ longitude for AOD measured by 4STAR (a-b), MERRA-2 (c-d), and GOCl (e-f) during KORUS-AQ matched to 
390 when the NASA DC-8 flew below $1 \mathrm{~km}$ altitude. The average AOD in each spatial bin is on the left panels (a, c, and e), while the right panels (b, d, and f) showcase the standard deviation of the observations within each spatial bin. The number of samples is represented by the size of the square symbol.

The aerosol properties during KORUS-AQ not only varied based on location, but also based on the meteorological period, see Table 1. The AOD was highest during the extreme pollution meteorological period and lowest during the stagnation period (Fig. 3). The dynamic/transport period has a dual peak of AOD, with a main peak below 0.1 , and secondary peak near 0.3 , all while having the flattest average AOD spectra which is linked to a high fraction of coarse mode aerosols (consequently lowest $A E$ in the legend of Fig $3 b$ ). The secondary peak of $A O D$ measured during the dynamic period, for $A O D$ higher than 0.2 , has an average $A E$ of 0.57 likely indicative of presence of coarse mode aerosol like dust influencing the highest AODs. The blocking period, while not the highest average AOD, had a mode at 0.5 , and had the steepest slope with respect to wavelengths, indicating a dominance of the fine mode aerosol in the column (Fig. 3b). The AE of different meteorological periods follows a similar tendency when measured by the ground-based AERONET in Korea during KORUS-AQ (Eck et al., 2020), for higher AODs with a greater proportion of fine mode aerosols going from May into June (Dynamic $\rightarrow$ Stagnation $\rightarrow$ Extreme pollution $\rightarrow$ Blocking, meteorological periods in order of May to June).

a)

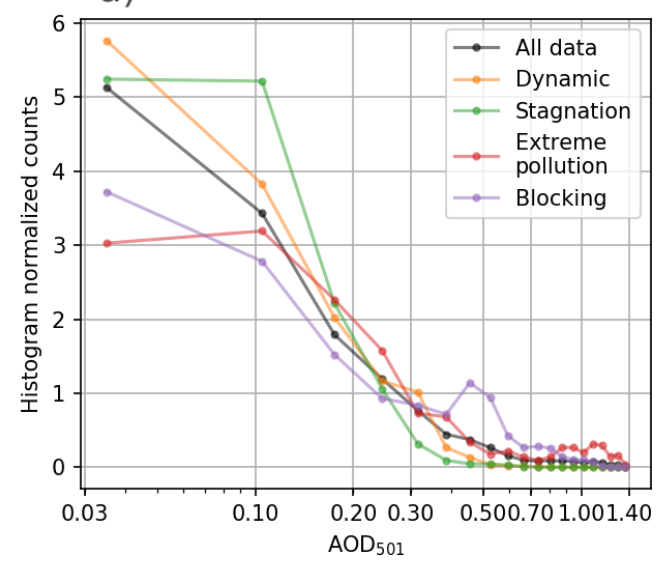

b)

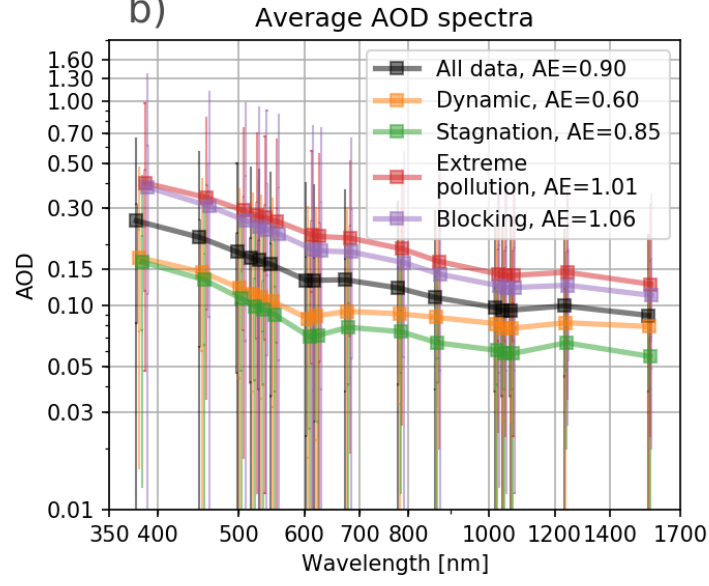

410 Figure 3 - (a) Histogram of AOD at $501 \mathrm{~nm}$ measured by 4STAR distribution from KORUS-AQ, separated by meteorological periods. (b) Corresponding AOD average spectra for each meteorological period, with the error bars denoting the range of AOD (excluding outliers) during that time period. The square symbols and error bars are slightly shifted from each other for clarity. The $A E$ in $b$ ) is calculated from the average spectra of each respective meteorological period from $453 \mathrm{~nm}$ to $870 \mathrm{~nm}$. 


\subsection{Along flight-path 4STAR measurements matches regional averages from GOCI and MERRA-2}

During KORUS-AQ, the NASA DC-8 was deployed for 44 consecutive days, of which 20 days were sampling days. While the NASA DC-8 is heavily instrumented to accurately observe the atmospheric composition, it was unable to measure the entire region during each flight. It is in consequence unclear how representative these airborne samples were of the broader region. To answer this question, we compared the overall average and the space and time matched observations observed by GOCl or modeled by MERRA-2 to the valid samples by 4STAR on board the NASA DC-8 (Fig. 4). The regional averages are defined by daily averaging of the GOCI or MERRA-2 over all of South Korea, while the flight averages are only the daily averages for the aerosol properties from GOCI and MERRA-2 that are collocated to the NASA DC-8 flight path for the days that were sampled by the airborne platform. While the flight averages miss the sporadic aerosols events apparent in the regional average time series from both $\mathrm{GOCl}$ and MERRA-2, the overall trend in AOD over the field study time period is well represented by the

430 flight averages. The difference between the $\mathrm{GOCl}$ flight average and the $\mathrm{GOCl}$ regional average showcases how well representative the flight sampling is to the broader regional average over Korea and neighboring waters.

Differences between averages from 4STAR and from the GOCl flight averages illustrate potential differences between the GOCI retrievals and the 4STAR measurements. Notably, the mean and median average AOD from GOCl regional and flight averages are nearly identical, while 4STAR AOD averages have a lower mean and median by up to 0.043 . Inversely the FMF from 4STAR is higher than GOCI by up to 0.07 , while the regional and flight averages are within 0.02 of each other. The low bias of GOCI for FMF and AE as compared to 4STAR is expected (see Fig. B1), particularly when the AOD is low (scene analysis e.g., Fig. 7 of Choi et al., 2016), 440 since GOCI YAER retrieval preferentially selects coarse-mode dominant aerosol models when there is limited signal. This low bias from GOCI FMF and $A E$ is also observed when comparing to AERONET retrievals (Choi et al., 2018). In addition to the already known AERONET comparisons over land, we find that the coarse mode AOD from $\mathrm{GOCl}$ is less correlated over ocean $\left(R^{2}\right.$ of 0.058$)$ than land $\left(R^{2}\right.$ of 0.066$)$. This low correlation is accompanied by nearly flat

445 slope when comparing GOCI to 4STAR coarse mode AOD over ocean $(0.20 \pm 0.04)$, and less so over land $(0.45 \pm 0.14)$, while the fine mode $A O D$ is much closer to the expected $1: 1$ line with slopes of $0.95 \pm 0.01$ and $0.99 \pm 0.06$ over ocean and land, respectively and low biases of 0.08 for all fine mode AOD (see Fig. B2). Albeit having a difference between 4STAR and GOCI, the small difference between $\mathrm{GOCl}$ regional and flight averages for FMF reinforces the 450 representativeness of the 4STAR samples within the Korean region.

The MERRA-2 mean regional AOD for the entire period of KORUS-AQ is biased high as compared to 4STAR AOD by nearly 0.1 , but when matched to flight days MERRA- 2 is biased low on average by 0.08 . The regional average MERRA-2 AOD is likely overestimated due to higher AOD on the later period of KORUS-AQ, with less frequent flights (see Fig. 4 lower left

455 panels). Similar high bias is observed when comparing the MODIS dark-target AOD retrievals, which is assimilated by MERRA-2, to AERONET measurements during KORUS-AQ (Choi et al., 2019). Both the regional average and the subsampled flight days AE from MERRA-2 are 
overestimated as compared to 4STAR by nearly 0.25 , suggesting a higher representation of fine mode aerosol in MERRA-2 than observed by 4STAR, while the opposite occurs for GOCI. A more thorough comparison of the AOD between 4STAR, GOCI, and MERRA-2 is presented in appendix B.
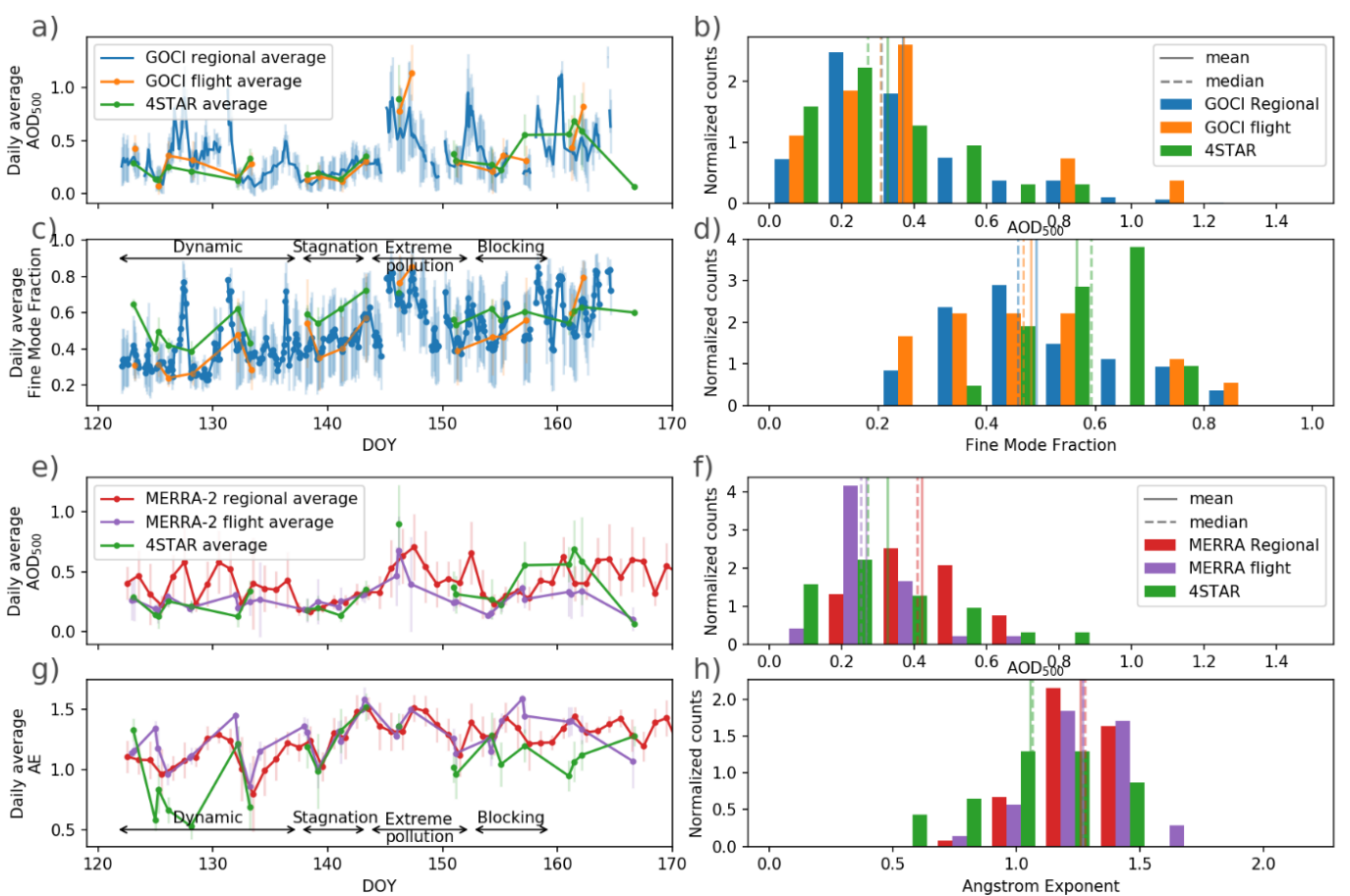

Figure 4 - The average $A O D$ at $500 \mathrm{~nm}$ and the FMF or $A E$ for the region observed during KORUS-AQ by 4STAR, GOCI (a,c), and MERRA-2 (e,g), as a function of day of year (DOY). The continuous time trace of the AOD (a) and FMF (c) for the GOCl regional average (for spatial bins centered from $33.8^{\circ} \mathrm{N}$ to $37.6^{\circ} \mathrm{N}$ and $124.3^{\circ} \mathrm{E}$ to $129.4^{\circ} \mathrm{E}$ ) is compared to the subset of GOCl matching in space and time (GOCl flight average) with the 4STAR for each day. 4STAR measurements are also compared to the daily averaged time trace for MERRA-2 AOD (e) and MERRA-2 AE (g), for either regional averages or the MERRA-2 subset for flight averages. Histogram of the averages based on regional and flight for GOCI AOD (b), GOCI FMF(d), MERRA-2 AOD (f), and MERRA-2 AE (h) presented in the time trace, with vertical solid lines denoting the mean, and dashed lines - the median. The meteorological periods are identified in $(\mathrm{c}, \mathrm{g})$ by the span of arrows relating to the edges DOY for each period.

During the 20 flight days, only two flight days have a difference of average AOD between the regional average and the flight average of $\mathrm{GOCl}$ data greater than the regional standard deviation (see Fig. 5). While the regional standard deviation can be sometimes large $(0.3$ around DOY 145, grey shaded region in Fig. 5), the average is closer to 0.1 during KORUS-AQ. There is no clear preference between over and underestimation of the $\mathrm{GOCl}$ flight average subset compared to the regional average, similar to the difference between 4STAR observations and GOCI flight average subset. Thus we can say that the sampling of AOD during 
the flights are representative of the greater Korean region for 18 out of 20 days.

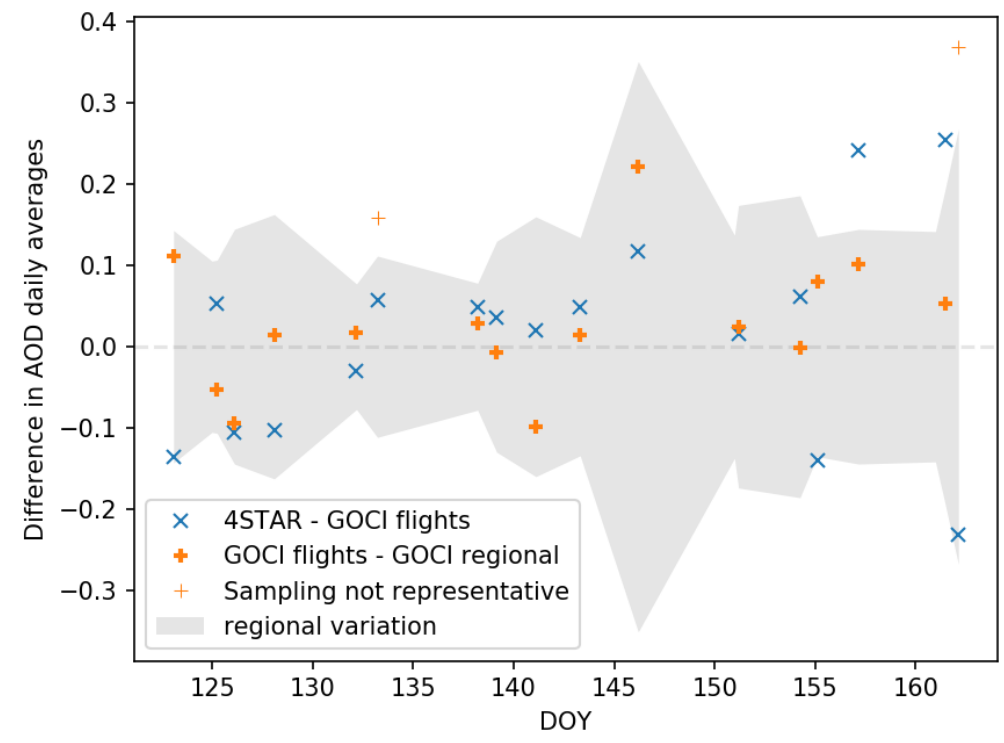

Figure 5 - Difference in daily average AOD as a function of the DOY depending on the sampling: GOCI regional averages, GOCI flights - subset to match spatial and time of flight observations, and differences between 4STAR matched to the GOCI flights. The grey shaded regions indicate one standard deviation of the AOD in the region as observed by $\mathrm{GOCl}$.

\subsection{Vertical variations in aerosol distribution}

Aerosol from local sources and transported from sources further away are likely to stratify vertically and have different optical properties, depending on aerosol age and source (e.g., dust from Gobi Desert). During KORUS-AQ, we observed that the largest contributor to total column AOD is near the ground, below $500 \mathrm{~m}$ (see Fig. 6) and has the largest slope of AOD with respect to wavelength (see below $0.5 \mathrm{~km}$ line in Fig. 6a). These aerosols have the highest fraction of fine mode, as would be expected from pollution-based aerosol, and new aerosol formation. The vertical distribution of AOD is a column measurement, representing the aerosol content between the measurement altitude and the top of atmosphere, thus the lower AOD spectra also incorporates the influence of the elevated aerosol layers, which are mostly influenced by coarser aerosol, as identified through the much lower AOD spectral slope. This is consistent with the observed aerosol transport at low altitudes consisting of pollution from more directly west, while higher altitudes flow was dominated by transport from more northerly

500 regions (Peterson et al., 2019). Natural stratification from the combined AOD statistics during KORUS-AQ, resulted in a slope change of the AOD spectra with observation altitude for AODs below $500 \mathrm{~m}$, above around $2 \mathrm{~km}$, and above $5 \mathrm{~km}$. 

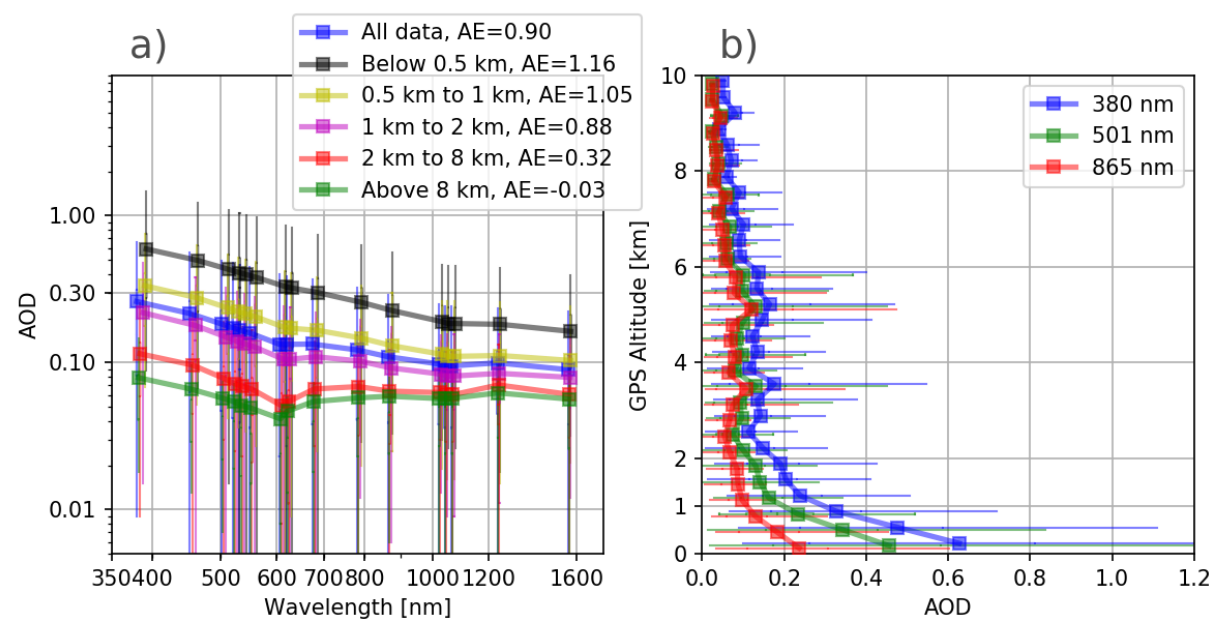

Figure 6 - Aggregated AODs observed during KORUS-AQ as a function of observation altitude, for (a) with average AOD spectra, and (b) binned vertically for a subset of wavelengths. The number of spectra per height bins in a) is $64736,41821,63130,121569$, and 31076 from lowest to highest respectively.

The stratification of the AOD as a function of altitude can be further examined in terms of the aerosol's fine and coarse mode contribution to the total AOD, which is obtained through the SDA extraction of the statistically aggregated observations of the AOD (Fig. 7). The impact on the vertical location of the observation is apparent in the probability distribution of fine and coarse mode AOD, where the fine mode AOD is responsible for nearly all AODs greater than 0.6 , and AODs greater than 0.6 are only observed below $500 \mathrm{~m}$. This large fine mode fraction is absent in observations of the atmospheric column starting at $2-5 \mathrm{~km}$ up to top of the

515 atmosphere. There is also a shift in the peak coarse mode fraction from $\sim 0.15$ to $\sim 0.05$ between $0.5 \mathrm{~km}$ and the $2-5 \mathrm{~km}$ layers (not shown), suggesting that the lowest portion of the atmosphere hosts a sizable portion of coarse mode AOD. 

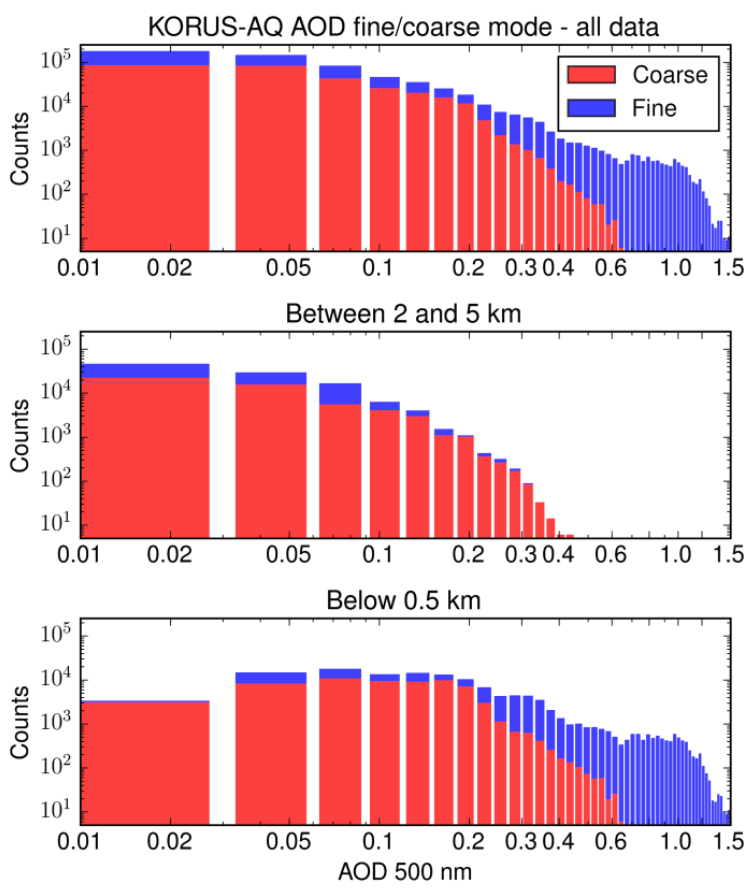

Figure 7 - Histograms of fine and coarse mode AOD measured during KORUS-AQ for all data (top), AOD measured between $2 \mathrm{~km}$ and $5 \mathrm{~km}$ (middle), and below $500 \mathrm{~m}$ (bottom). The total length of the histogram bar indicates the total $A O D$ in that bin, while the red/blue differentiation indicates the portion of the total AOD due to AOD from either fine or coarse mode aerosol.

During the multiple-month deployment, the relationship between fine and coarse mode aerosols at different altitudes shifted with time and changing meteorological periods. The proportion of the impact of fine and coarse mode aerosols on AOD is also illustrated with AE (Fig. 8), which is inversely proportional to size. Notably, the dynamic meteorological regime showcases the largest $A E$ at the highest altitude (smaller particles than other periods), while the smallest $A E$ is observed at high altitudes during the extreme pollution / transport meteorological period, which coincides with long range transport of aerosol. The low $\mathrm{AE}$ at high altitude suggests that the largest particles are transported, which supports the back-trajectories and meteorological estimate from Peterson et al. (2019) showing transport from northeast during this timeframe. The dynamic period shows a large variation in $\mathrm{AE}$ at higher altitudes, but may still be influenced by dust emissions, which have been shown to have relative variations on $A E$ dependent on dust layer-height, related to the transport pathways (Shin et al., 2015). The extreme pollution / transport regime shows a stratification of the aerosol layer for small AEs at lower altitudes (below $2 \mathrm{~km}$ ) than all the other periods, suggesting that the coarse aerosol mode dominates the column well below average altitudes during this meteorological regime. Other notable features are during the blocking period, the AE is similar to the overall averages from $2.5 \mathrm{~km}$ upward, while diverging to a higher $A E$ in the lower portion of the atmosphere than the KORUS-AQ average. The largest interquartile spread in binned AEs is observed in the range between 1.5 
$\mathrm{km}$ to $3 \mathrm{~km}$, while the dynamic meteorological period represents the largest interquartile range for most of the upper atmospheric observations (above $3 \mathrm{~km}$ ). Similar vertical dependence as separated by meteorological periods has been shown by measurement of small aerosol particles acting as cloud condensation nuclei (Park et al., 2020a).

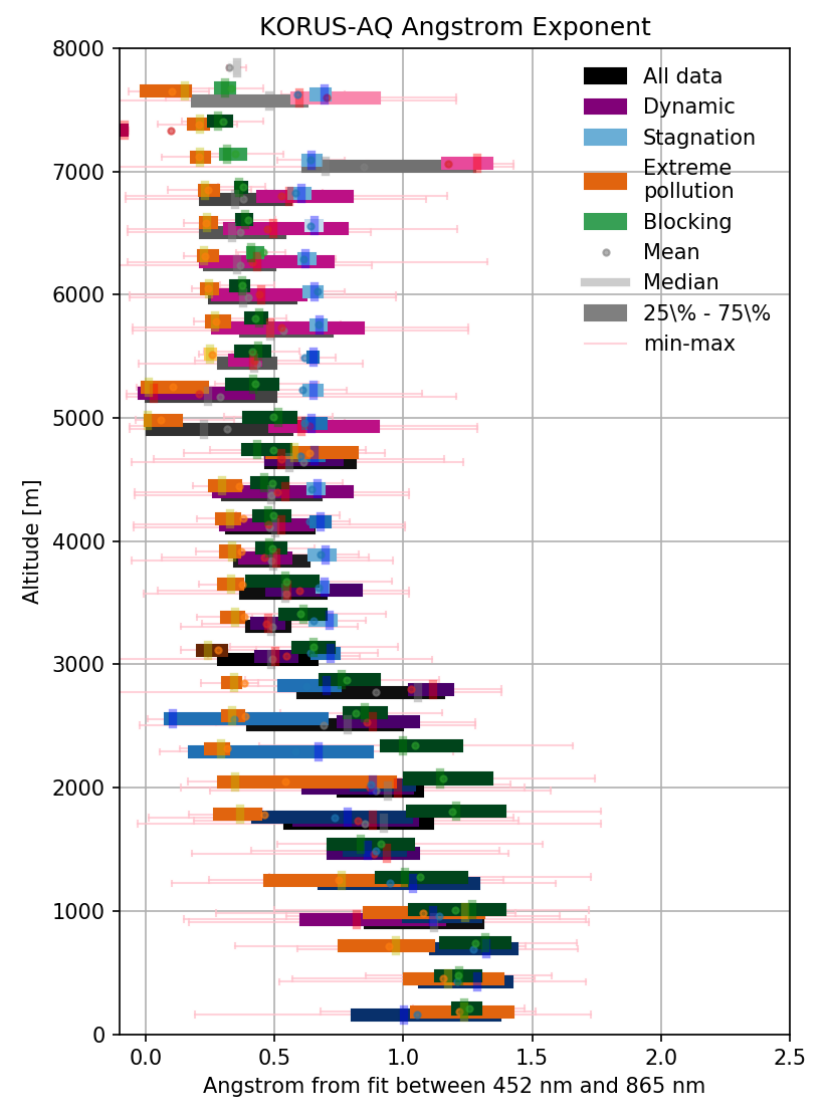

Figure 8 - Angstrom Exponent (AE) box-plot distribution measured at different altitudes separated by different meteorological periods, during KORUS-AQ, and for all data (black). The number of days sampled within each vertical bin and meteorological regime is illustrated by the shading of the color. The vertical bar indicates the median of each altitude bin, while the center dot represents the mean. The interquartile range of the data in each vertical bin is represented by the thick horizontal bar. The range of values observed at the given altitude is presented as horizontal, colored, error bars.

\subsection{Autocorrelation distances of intensive and extensive aerosol properties} Aerosols in the Korean peninsula region are subject to processes linked to their sources, sinks, and evolution. For aerosols subject to relatively minor evolution (e.g., dust with no photochemical aging and few removal processes), but large transport distances, the 
autocorrelation distances are commensurate to the transport distances, and one would expect the inverse to be also true. For aerosols subject to only transport, the intensive properties are expected to remain constant, such as size, mass absorption efficiency, and index of refraction, but the total concentration within a column, impacting the AOD, would change due to dilution and removal of the aerosol (e.g. via rain out or dry deposition). For example, dust aerosol transported from mainland China, which after initial growth with chemical and morphology changes near source, have near constant intensive properties but experience dilution causing reduction in AOD, but no change in spectral dependence. This same dust transported from 565 mainland China may experience external mixing with the fresher pollution from Korea (Heim et al., 2020), would both impact the AOD and its the spectral dependence at scales commensurate to the mixing region. Alternatively, for local aerosol production and growth, both the intensive properties and the extensive column aggregate properties, like the AOD, will vary within small distances, akin to the size of the source region and the rate of the secondary organic aerosol

570 production. Even advected aerosols from the surrounding region will undergo local processing, such as hygroscopic growth, particularly in Korea for ammonium sulfate, ammonium nitrate, and organic aerosols (Saide et al., 2020), which impact intensive properties (size and AE) within a small distance, while simultaneously increasing the AOD extensive property. Figure 9 shows the autocorrelation as a function of distance of the aerosol properties measured and modeled

575 during KORUS-AQ, along horizontal flight segments of the NASA DC-8 where there are 4STAR observations that are quality assured.

The extensive aerosol property investigated here is column AOD, and the intensive aerosol property is $A E$, which is inversely proportional to aerosol size and dependent on aerosol refractive index (e.g., Saide et al., 2020). The autocorrelation-distance distribution of AE is 580 nearly identical to the FMF of the aerosol for the remotely sensed products. All data points used to build these relationships were first matched in time and location to the NASA DC-8 horizontal flight segments.

From Fig. 9, we see that the extensive aerosol property, AOD, has a high correlation, over longer distances (e.g., R>0.85 for distances up $25 \mathrm{~km}$ from 4STAR) than the intensive aerosol

585 property, AE, $(R>0.85$ for distances up to $7.5 \mathrm{~km}$ from $4 S T A R)$. This difference between a consistently high autocorrelation over longer distances is particularly evident in the in situ data, but is reproducible with all observations/model. This is partly counterintuitive to the general notion (as described by Anderson et al., 2003) that aerosols have more consistent intensive properties from particular point sources, than their extensive counterparts. We find here that

590 aerosol concentration is less variable than their size. While there are industrial point sources west of Seoul, most sources of aerosol impacting air quality are due from diffuse (e.g., secondary formation from traffic and transport emissions) or from long range transport. From these samples during KORUS-AQ, the total column AOD is more consistent over a greater area than aerosol size, and consequently type. This may be linked to the notion of AOD and aerosol 595 concentration is regulated mostly by the combination of long-range transport and changes in local sources, which are in turn modulated by the meteorological periods (e.g., Peterson et al., 2019). The local aerosol production and aerosol evolution/transformation may be more related to the underlying processes and changes in dominant aerosol types, that impact aerosol at shorter distances, and consequently timescales, than the transport process (Heim et al., 2020). 
600 The shortest autocorrelation distances are subject to both the random noise from instruments and retrievals, and the natural variability of the observed physical property (Anderson et al., 2003). The best-case scenario is to have autocorrelation values near 1.0 for the shortest distances, indicating low natural variability and low noise from the observations/models. In this comparison, since the observable quantity is consistent, the same natural variations should be present for all of the observations/models, therefore any reduction in autocorrelation can be attributed to the method's smallest observable distances and source of random noise. For sake of comparison of the physical processes, we opt to mostly ignore the autocorrelation at the shortest distances except to serve as a baseline upper-bound of the autocorrelation that can be resolved by MERRA-2, 4STAR, GOCl, and in situ sampling. In this comparison (Fig. 9), both

610 MERRA-2 and 4STAR have near 1.0 autocorrelation at the shortest distances, while GOCl and the in situ observations have lower values. This high initial value in autocorrelation can be interpreted as an upper bound of autocorrelation values that can be resolved by those methods. While MERRA-2 is interpolated to match 4STAR sampling, the native pixel resolution is still at roughly $59 \mathrm{~km}$, thus results referring to distances shorter than that may be more indicative of the

615 interpolation methods (Collow, et al., 2020) than the native modelling processes.

For all data observed and modeled during KORUS-AQ, the AOD at $500 \mathrm{~nm}$ wavelength $\left(A O D_{500}\right)$ shows the longest distances with high autocorrelation, as compared to the AE (Fig. 9). The absolute magnitude of the autocorrelation for the observations and model is not as instructive as the relative decrease with distance. In both the AOD and AE autocorrelation, we

620 include the measure from the in situ aerosol extinction coefficient, representing the aircraft-level measurement. As expected, because of the integrating effect of the column values and the increased sampling volume, 4STAR, MERRA-2, and GOCI values have longer distances with high autocorrelation, while the in situ aerosol extinction coefficient (AOD equivalent for point measurements) and $\mathrm{AE}$ have decreased autocorrelations at shorter distances. However, at 625 longer autocorrelation distances, the autocorrelation of AOD (at $>20 \mathrm{~km}$ ) and AE (at $>2 \mathrm{~km}$ ) from $\mathrm{GOCl}$ mirror those from the point-like in situ measurements of the aerosol extinction coefficient.

To account for potential sampling biases, a subset of 91 segments $(30 \%)$ of the total 302 horizontal flight segments, comprising 583,183 samples, were randomly selected via Monte

630 Carlo sampling, and repeated for building a 50-member ensemble. The ensemble mean and standard deviation are interpreted as the potential impact due to changing the selection of samples (Shinozuka and Redemann 2011). We observed relatively small autocorrelation divergence from the majority of dataset subsamples at the shortest distances (represented by the vertical error bars, Fig. 9). The standard deviation of the Monte Carlo sampling is largest for 635 the longest distances, where fewer of the horizontal segments span that length. The standard deviation of the ensemble sampling is smallest on average for $A E$ than $A O D$, for all observations and models except for 4STAR derived values, with MERRA-2 showing the least dependence on sampling biases. The larger deviation of 4STAR AE than AOD within the Monte Carlo sampling is because $A E$ is more variable and the AOD as measured by $4 S T A R$, this may 640 be caused by smaller AE range is available for $\mathrm{GOCl}$ or MERRA-2 due to their confined number of aerosol microphysical models, and that the in situ observations may be limited to a subset of the aerosol due only sampling aerosol at the aircraft level. 4STAR's column measurement may 
also reflect the influence of multiple aerosol sources and types (e.g., dust over pollution) that are not represented in modeled, retrieved, or at-aircraft-level in situ measurements, some of that variation can be observed in Fig. 8.

Both MERRA-2 and 4STAR show similar autocorrelation over a wide distance range for AOD, with the $85^{\text {th }}$ percentile point (where autocorrelation is reduced by $15 \%$ ) occurring at $130 \mathrm{~km}$ (Fig. 9). Even though MERRA-2 uses assimilation to link its model representation to the observed world using MODIS and other remote sensors, it still shows the longest distance with a consistently high autocorrelation. Even when accounting for the 50-member standard deviation the MERRA-2 AOD autocorrelation only overlaps with the 4STAR AOD mean-member at distances longer than $60 \mathrm{~km}$. For AE from both MERRA-2 and 4STAR, the standard deviation and mean of the member ensemble do not overlap until distances of $>60 \mathrm{~km}$, with MERRA-2 showing consistently higher autocorrelation than observed by 4STAR. The GOCl observations show a much shorter autocorrelation distance at the $85^{\text {th }}$ percentile for AOD, just shy of $20 \mathrm{~km}$, at which the overall trend follows the point-like in situ observations by LARGE. This is observed with both the $A O D$ and $A E$ autocorrelations. The $A E$ autocorrelation decreases at shorter distances compared to AOD for all samplings (MERRA-2, 4STAR, GOCI, and in situ), with much higher downward slopes. MERRA-2 AE also shows a distinct inflexion in autocorrelation at 30 $\mathrm{km}$, while 4STAR, GOCl, and in situ all show a constant steeper slope. The average distance to decrease autocorrelation by $15 \%$ for AOD of all methods is $65.0 \mathrm{~km}$, for AE it is $22.7 \mathrm{~km}$.
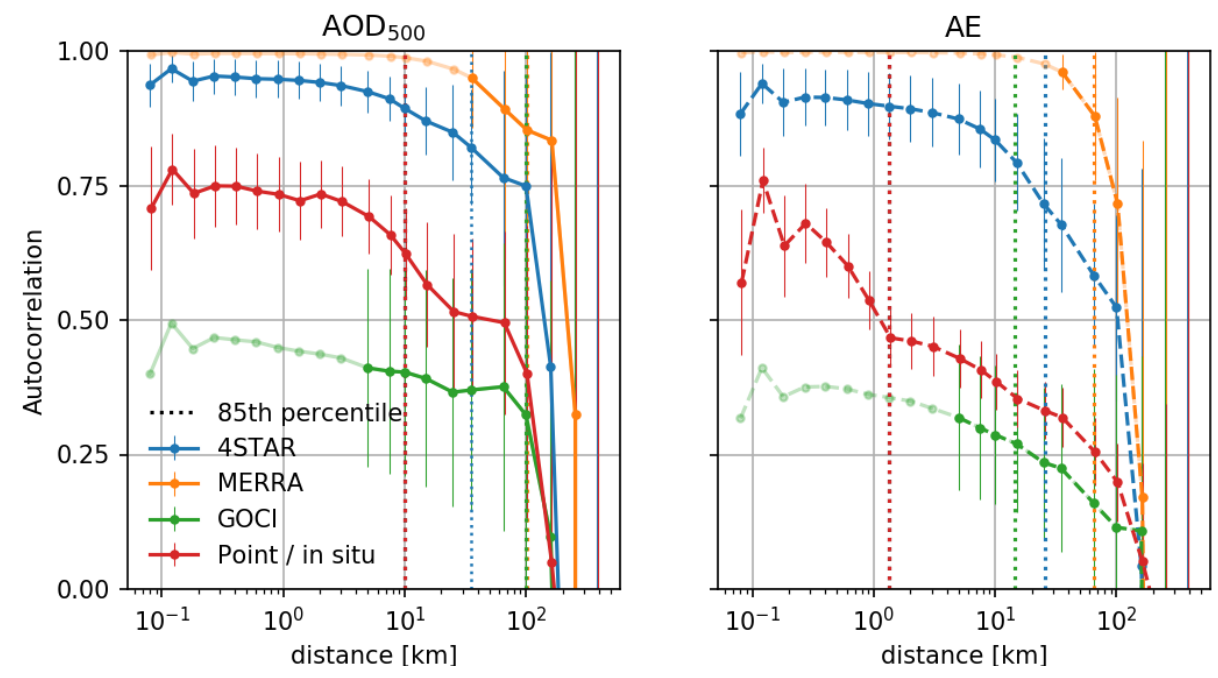

Figure 9 - The autocorrelation distances of the aerosol properties measured and modeled during KORUS-AQ, separated by either aerosol intensive properties (right, $A E$, relating to aerosol size, dashed lines) or extensive properties (left, column AOD, solid lines). The point / in situ denotes the autocorrelation from the aerosol extinction coefficient instead of the column values of all others. The colors denote the source of the data presented here. The vertical error bars represent the standard deviation of the 50 -member ensemble Monte Carlo subsampling at 
$30 \%$ of flight segments. The vertical dotted lines represent the autocorrelation distance of the $85^{\text {th }}$ percentile, which is the location that the autocorrelation is reduced by $15 \%$ when compared to the autocorrelation of the shortest distance. The lighter colored lines for $\mathrm{GOCl}$ and MERRA-2 represent the autocorrelation for distances smaller than the diagonal length from one pixel center to another, which are closest to the NASA DC-8 flight path.

What remains to be clarified are the differences between our current understanding of aerosol point-sources and their combined impact on meteorology, vertical distribution of aerosols, and aerosol speciation.

\subsection{Untangling the impact of meteorology, altitude and speciation on autocorrelation}

680 The average AOD during KORUS-AQ is dependent on the meteorological regime (Fig. 3) and the vertical sampling (Fig. 6). The AOD vertical distribution of fine and coarse mode aerosols (Fig. 7) is a driver for changes of $A E$ as a function of altitude and combined together for the total column. However, the AE vertical distribution is also dependent on the different meteorological periods (Fig. 8). Here we show the autocorrelation distances of the AOD and FMF, as a function

685 of meteorological periods and sampling altitude for a variety of observations and models (Fig. 10). For easier comparison we opted to show the autocorrelation normalized to the shortest distance, since reduction in autocorrelation over varying distances was the main focus, and less the resolution of the instrumental noise. Additionally, the autocorrelation distances as reported by Shinozuka and Redemann (2011) for the long-range transport from Arctic observations and

690 local biomass burning in the Canadian Boreal Forest are included for reference (SR2011 Long, SR2011 Local; respectively).

Random sampling of the level flight segments allows illustration of the range by which the autocorrelation depends on the specific flight segments. The most variability is observed at the longest distances where there are fewer samples from the flight segments (Fig.10). Significant

695 changes between the autocorrelations are observed for the varying meteorological periods, with the blocking period having the shortest distance which was negatively correlated with both the AOD and FMF. The blocking period, which experienced a high-pressure ridge diverting much of the mid-latitude storm tracks away from Korea but with the highest average surface temperature and with most days having a cloud fraction over $50 \%$, is also the only period when the distance

700 to $85^{\text {th }}$ percentile autocorrelation for MERRA-2 AOD is the same as for 4STAR AOD. This last time period, may be subject to largest variations in both AOD and FMF due to rapid aerosol growth by water vapor condensation on the aerosol particles, and amplification of secondary aerosol formation, that occur in the warm and humid Korean summertime (Koo et al., 2021; Jordan et al., 2020).

705 The meteorological period with the preceding longest distance at high autocorrelation was the dynamic period. While this is true for both AOD and FMF, the FMF behaves less monotonically than AOD autocorrelation, with larger variations with the Monte Carlo subsampling that encompasses different flight legs with potentially different aerosol composition. The largest difference between autocorrelation of AOD from 4STAR and MERRA-2 occurs during the 
710 stagnation period, which had a significant anticyclone flow over Korea. This would suggest that MERRA-2 either undervalues the removal processes of the aerosol during that period, or that the AOD sources are less consistent than what is expected by the model. The stagnation period, which was a particularly dry but hot period, also has the second shortest distance with high autocorrelation of FMF (repeated by both 4STAR and GOCI), indicating a high variability of

715 the aerosol size during this time. The dry conditions were unlikely to be favorable for secondary organic aerosol formation (Liu et al., 2018), but the heat of the day contributed to mixing depths of 1500-3000 m (Peterson et al., 2019), which would point to changes in aerosol removal processes in MERRA-2 rather than sources, however persistent clearer skies, obscured by some dust but less clouds, may promote photochemistry in tandem with the inflow of ozone 720 from sea breeze near Seoul. This period is also identified has having significant changes in vertical mixing, which in turn impacts the containment and distribution of aerosol (Jordan et al., 2020). The representation of the vertical mixing depth in MERRA-2 could be influential to it's autocorrelation representation.

For all periods, GOCI presented lower autocorrelation than 4STAR for both AOD and FMF, and 725 notably going lower during the blocking period than the reference SR2011 Local, which focused on wildfire/biomass burning events in Canada. This may be explained by the selection criteria for GOCI AOD retrieval, which returns the mean of the 3 best aerosol model (Choi et al., 2018), and at the same time accounts for variations in surface albedo.

While mostly following the same autocorrelation trends with distance as 4STAR AOD and FMF, $730 \mathrm{GOCI}$ AOD and FMF have higher autocorrelation during the extreme pollution/transport period than the dynamic period which boasts the highest autocorrelation for 4STAR and MERRA-2. These consistently high autocorrelation over large distances for the extreme pollution and dynamic periods ( $12.6 \mathrm{~km}$ and $15.2 \mathrm{~km}$, respectively, with $\mathrm{r}(\mathrm{AOD})$ above 0.85 from 4STAR) in combination with the low average $\mathrm{AE}$, matches the expectation of dust aerosol transported from

735 long distances (Peterson et al. 2019). For these periods, the autocorrelation remains higher for longer distances for the FMF than the AOD, likely indicating that transformation of the aerosol size is not significantly affected during transboundary transport, e.g. no significant rain out, new particle formation, or particle growth. While there are evidence of pollution aggregating on dust particles (Heim et al., 2020), this would be less impactful to the autocorrelation than aerosol

740 processes occurring during the blocking period. The blocking period is notable because of the shortest distance with high autocorrelation for the FMF (3.5 km with r(FMF) greater than 0.85 observed by 4STAR), likely resulting from a variable combination of secondary aerosol formation, deeper vertical mixing from episodic and cloud processing of the aerosol similarly to PM2.5 (Jordan et al., 2020). These processes would result in rapid change in particle size, and 745 thus shorter distances with high autocorrelation. Since these processes occur regionally for distributed sources on the Korean peninsula, we find that the distances of aerosol size change is smaller than those for change in optical depth $(8.0 \mathrm{~km}$ with $\mathrm{r}(\mathrm{AOD})$ greater than 0.85 observed by 4STAR). This is likely from a combination of factors, including AOD from new particle formation more than compensates for aerosol dilution, similarly to that found downwind

750 of Canadian oil sand processing centers (Baibakov et al., 2021). For the distances reported, there are no periods exhibiting higher autocorrelation than those sampled from long-range transport in the arctic (SR2011 Long). 
The autocorrelations for both AOD and FMF, as segregated by altitude, have nearly indistinguishable behavior for distances shorter than $10 \mathrm{~km}$. The altitude dependence of the autocorrelations shows that the highest sampling (greater than $3 \mathrm{~km}$ altitude) had the longest autocorrelation, as expected, likely due to the being affected mostly by long-range transport than local sources (Fig. 10b). The aerosol observed at the mid-layer (1-3 km) has the shortest distances with high autocorrelation. The vertical mixing height was predominantly around $1 \mathrm{~km}$ during the dynamic and transport periods, but increased to nearly $3 \mathrm{~km}$ at Seoul during periods coinciding with shorter distances of high autocorrelation (stagnant and blocking) (Peterson et al., 2019; Jordan et al., 2020). The reduction in autocorrelation is likely a result of the changes in mixing layer height. The FMF for all altitudes had a more gradual decrease in autocorrelation over the whole range of distances than for AOD, while the autocorrelation for AOD dropped more precipitously. Consistent with Fig. 9, the GOCI AOD and FMF have lower autocorrelations for set distances than the 4STAR and MERRA-2 counterparts.
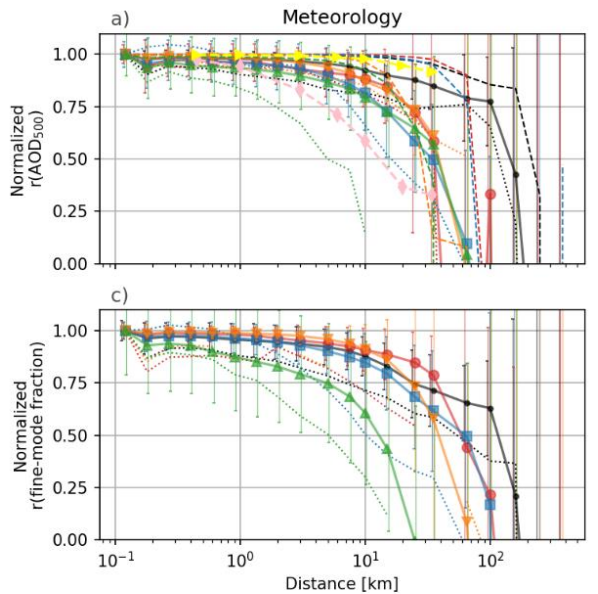

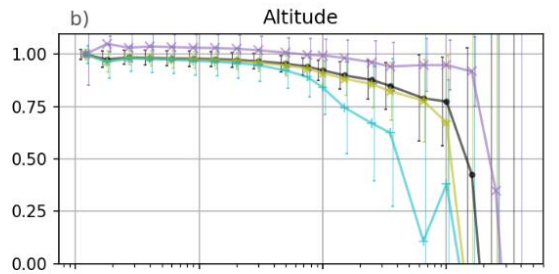

Meteorology $\rightarrow$ All $\rightarrow$ Dynamic - Stagnation $\checkmark$ Extreme pollution
$\ldots$ Blocking $\triangle$ Blocking -7)- SR 2011 Local ...... GOCI YAER V2 -..... GOCI YAER V2

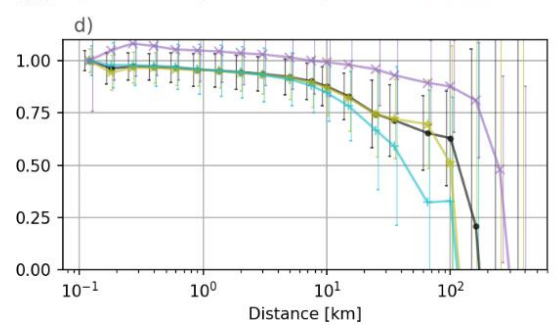

Altitude - All * 0-1 km $\begin{array}{r}+1-3 \mathrm{~km} \\ +\quad 3+\mathrm{km} \\ \hline\end{array}$

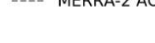

Figure 10 - Autocorrelation of aerosol properties during KORUS-AQ, separated by meteorological time periods on the left-hand panels, and separated by altitude on the right-hand panels, with top panels representing the autocorrelation of extensive AOD properties and the bottom panels representing the intensive properties. The vertical error bars indicate the standard deviation of the autocorrelation computed using a 50-member Monte Carlo ensemble.

Figure 11 shows the distances that the autocorrelation for speciated AOD were reduced by $15 \%$, or at the $85^{\text {th }}$ percentile of the first autocorrelation value (as represented by the vertical dotted lines in Fig. 9). These $85^{\text {th }}$ percentile distances are the median values of the 50 -member ensemble. We represent the 4STAR and GOCI AODs as separated by their portions due to either fine mode or coarse mode aerosols. Including the MERRA-2 AOD enables understanding of the AOD contributions from multiple aerosol types: dust and sea salt compared to optically defined coarse mode aerosol (top panel Fig. 11), as well as sulfates, black, and organic carbon 
distance is calculated based on data from the different meteorological periods (all at altitudes below $3000 \mathrm{~m})$.

Autocorrelation distance at 85th percentile for speciated AOD
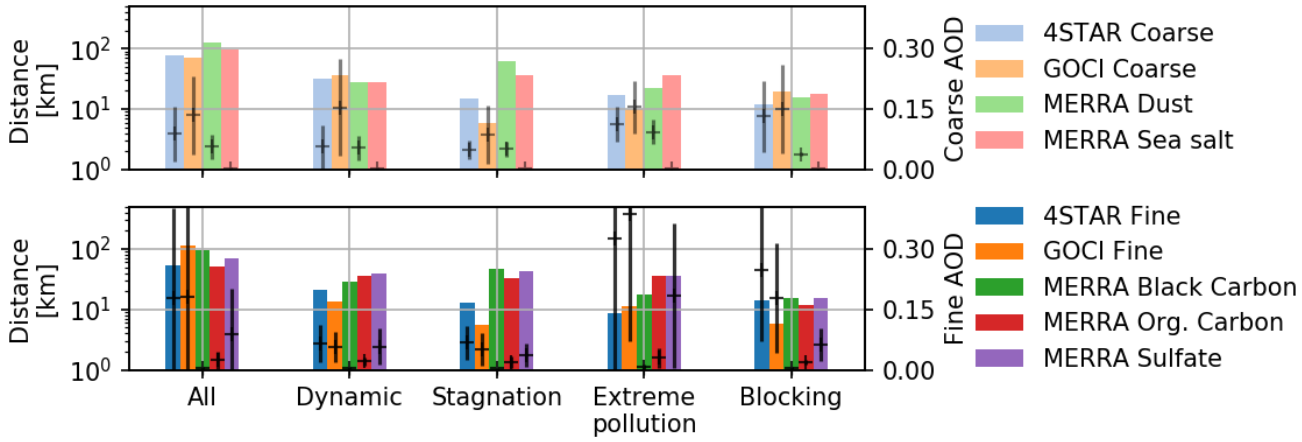

Figure 11 - The distance for the $85^{\text {th }}$ percentile autocorrelation, or which the autocorrelation is decreased by $15 \%$, for a variety of speciated AODs, including fine and coarse mode AOD for 4STAR and GOCI, and dust, sea salt, black carbon organic carbon, and sulfate contributions to AOD for MERRA-2. These are separated by the meteorological periods. The black symbols for each aerosol species indicate the average AOD, and the standard deviation (as error bars), with respect to the right-hand side $y$-axis.

790 Of all the meteorological periods observed during KORUS-AQ, the dynamic period (first sixteen days of May 2016), showcased the largest distances with autocorrelations higher than $85 \%$, and consistently amongst model, satellite, and 4STAR observations, even when discretized between various aerosol types, at $31.5 \mathrm{~km} \pm 2.7 \mathrm{~km}$ ( $20 \%$ bin size). The stagnation period, while having much lower average AOD, still showcased very similar $85^{\text {th }}$ percentile autocorrelation distances,

795 except for $\mathrm{GOCl}$, which showed longer distances than during the blocking period, which had more AOD from sulfate aerosol as reported from MERRA-2. The distance of autocorrelation at $85 \%$ for fine mode AOD for the combination of all KORUS-AQ demonstrates a high degree of consistency between 4STAR, GOCI, and MERRA-2 sulfate, and, to a lesser degree, organic and black carbon AODs (Fig. 11). The extreme pollution meteorological pattern boasts the 800 lowest $85^{\text {th }}$ percentile with autocorrelation distances from all meteorological patterns, and the coarse mode having shorter distances than the fine mode. During this time period, the greatest proportion of AOD is attributed to sulfates by MERRA-2, with similar autocorrelation distances as determined by 4 STAR, while the GOCI average AOD is overestimated during that time period. The $85^{\text {th }}$ percentile distance for the fine mode AOD from 4STAR seems to be 805 consistently shorter than modeled by MERRA-2, except for the AOD due to black carbon, which also boasts a lower average AOD (black horizontal line, Fig. 11). When comparing the mean AOD from MERRA-2 by species to the different periods, the same trends (for aerosol mass density) appear of the chemical composition of particle matter of less than 1 micron aerodynamic diameters as measured at a ground site in Seoul (Jordan et al., 2020). While not 810 exactly a one-to-one comparison, the sulfate AOD during the blocking period is greater than the average, while the reported mass density for sulfates is slightly lower than the average at the surface during that same period. 


\section{Conclusion}

The AOD measured during KORUS-AQ by airborne sampling using 4STAR, satellite remote sensing using $\mathrm{GOCl}$, and reanalysis from MERRA-2 was found to follow general climatological trends for the Korean peninsula (Choi and Ghim, 2021). The aerosol intensive properties are also observed during KORUS-AQ, particularly aerosol size (fine or coarse mode) and related $A E$. We present the general trends in AOD and AE/FMF sampled over the duration of KORUS$A Q$, and show the vertical dependence, the impact of meteorological periods, and the

820 autocorrelation as a function of distance for level flight legs. The spatial distribution of AOD was mostly matched between 4STAR, GOCI and MERRA-2, with the highest AOD in the Yellow Sea and near Seoul, and the lowest AOD observed just south and also directly east of the Korean peninsula. Comparing the sampling by the NASA DC-8 to GOCI and MERRA-2 regional averages and subsets of observations matched to the NASA DC-8 flight paths, we observed

825 that 4STAR AOD was representative of the regional average and variability for 18 out of 20 days, while the FMF from 4STAR showcased a high bias compared to the subsets of $\mathrm{GOCl}$, and AE has a low bias compared to MERRA-2. The relatively low GOCI FMF compared to 4STAR corroborates with the findings from Choi et al. (2018) when comparing to AERONET sites.

The highest AODs were observed during the extreme pollution period (25-31 May), where

830 transport was observed alongside haze formation (Peterson et al., 2019). This high AOD period was also observed using ground-based AERONET sensors (Choi et al., 2021; Lee et al., 2018). This meteorological period had the lowest $A E$ at high elevations, suggesting lofted dust or other coarse mode aerosol, consistent with back-trajectories (Peterson et al., 2019). When observing the distance at which the autocorrelation of the extensive (AOD) and intensive (FMF/AE)

835 properties are reduced by $15 \%$, the meteorological periods seem to be the primary drivers, with the extreme pollution period showing the smallest distance. While there are variations between 4STAR, GOCI, MERRA-2, and in situ measurements, this shortest distance is observed during the extreme pollution, with the intensive properties showing shorter distances for a $15 \%$ decrease of autocorrelation of extensive properties.

840 During the stagnation meteorological period (17-22 May), we observed the lowest AOD (similarly to Choi et al., 2021), and the highest AE at elevated observations. The high AE is likely due to lofted small size aerosol. While this period showcased smaller aerosols in the column, it also hosted the longest distances at which the autocorrelation remained above $85 \%$ at its lowest value. This long distance, was rivaled only by the blocking period (1-7 June), and

845 was reproduced in all of our observation methods (4STAR, GOCI, MERRA-2, and in situ).

Throughout the entire period, the AOD due to fine mode aerosol constituted the largest contributor to AOD at lower altitudes (below $0.5 \mathrm{~km}$ ), while the AODs due to coarse mode aerosol were predominant in the lofted vertical region $(2 \mathrm{~km}-5 \mathrm{~km})$. The exact distribution of fine and coarse mode aerosols was modulated during the different meteorological periods, with

850 the altitude region between $1.5 \mathrm{~km}$ and $3 \mathrm{~km}$ showing the largest variability in FMF. Throughout the entire period, the distance at which a decrease of autocorrelation is observed to be consistently shorter for intensive properties than extensive, repeatable with 4STAR, GOCI, and MERRA-2. To account for potential sampling bias, we computed this distance and the autocorrelation by using a Monte Carlo ensemble of the level flight legs, and reporting its mean and standard deviation. This suggests that, contrary to commonplace opinion, when dealing with a region where there are aerosols from multiple sources, the intensive properties are not as 
consistent over long distances as the extensive aerosol properties. Satellite algorithms that assume that aerosol size does not vary as much as aerosol optical depth should be reassessed.

860 Appendix A: Measurement quality and corrections

\section{A.1 4STAR Aerosol Optical Depth derivation}

AOD is calculated using the inversion of direct solar transmittance measured by 4STAR while actively tracking the sun on board the NASA DC-8. The simple inversion process is based on the refined Beer's Law but is subject to multiple correction procedures, namely the correction of transmittance, based on the variability of transmittance influenced by the Fiber Optic Rotating Joint (FORJ), the non-linearity of the spectrometer, the removal of the trace gas column impact on the AOD spectra, and the correction of the transmittance change due to unwanted material deposition on the 4STAR window, similarly described by LeBlanc et al. (2020).

\section{A.1.1 FORJ correction and gas phase optical depth}

870 Sunlight entering the 4STAR Gershun tubes is propagated to the spectrometers using low-loss multimode optical fiber bundles and other fiber optic components. The FORJ is part of the light path that allows endless rotation of the 4STAR sun-tracking head azimuthal position, with respect to the fixed geometry of the aircraft fuselage, where the rest of the 4STAR instrument is located. The FORJ introduces variability, which includes angle dependent hysteresis and some

875 random noise, in the transmission due to this azithumal position, and can be corrected. The correction is computed from the azimuthal dependence through measurements of a stable light source (a light emitting diode that has less than $0.1 \%$ variation in radiance during the time of the test) in between each flight by a full rotation in each direction. The variations have a near sinusoidal shape with features departing from the mean by no more than $+/-1.4 \%$ and are

880 repeatable in between each measurement (within $0.4 \%$ over the course of the field mission), with the largest features not moving by more than $20^{\circ}$.

$A O D$ is influenced by trace gas absorption in the entire column in distinct wavelength regions. We correct the influence of trace gas $\left(\mathrm{NO}_{2}, \mathrm{CO}_{2}, \mathrm{O}_{3}, \mathrm{O}_{2}-\mathrm{O}_{2}, \mathrm{CH}_{4}\right)$ by convolving their retrieved vertical column gas abundance and profile with their spectral absorption coefficients (Segal

885 Rozenhaimer et al., 2014). This result in an optical depth contribution from these gases (typically very minor) which is then subtracted from the AOD spectrum.

\section{A.1.2 Updated 4STAR light path instrument design for thermal stability} Prior to the KORUS-AQ deployment, the 4STAR flight path was improved using funding from the ESTO Airborne Instrument Technology Transition (AITT) program to reduce variability in the

890 transmission of the optical path. Notable modifications include improved fabrication processes for the fiber optic assemblies, and improved polishing and cleaning of the fiber optic ends and direct beam diffusing element to ensuring a flat field of view (less than $1 \%$ deviation over $1^{\circ}$ ) for sampling the solar direct beam.

Fiber optic assembly modifications include annealing of the PEEK jacketing to reduce the

895 degree of dimensional creep induced by the considerable thermal cycling exposure, the use of thermal epoxy heat shrink tubing to reinforce the jacket-to-connector interfaces, and careful control of the fabrication geometry to ensure that there is sufficient radial clearance in the coils 
to accommodate the thermal expansion differential between the fused silica fiber and the PEEK jacket, to avoid thermal-induced stresses and resultant microbending losses and connector reliability in the light path, for temperature ranges from $-50^{\circ} \mathrm{C}$ to $+50^{\circ} \mathrm{C}$. The fiber optic ends have been repolished to ensure minimal light scattering and a high degree of flatness for each of the fiber optic bundle endfaces that link the spectrometers and the optical inlets (see Fig. A1, for before and after fiber optic bundle example). Additionally, procedures were adopted for the preparation, curing, polishing, inspection and cleaning of the fiber optic connectors.

905
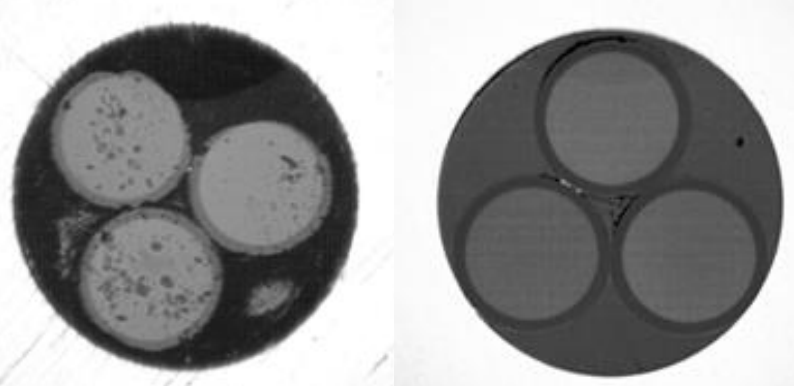

Figure A1 - Image of 3-element fiber optic bundle endface that is part of the solar direct beam measurement optical path of 4STAR. Before polishing is seen on the left, while after polishing on the right. The uneven fiber flatness, severe contamination and pocked endface increased

910 scattered light and was linked to distortions in the instrument field of view. The polished fiber face has a very planar endface, with no pocking and contamination resulting in a much more predictable light measurement.

Prior to KORUS-AQ, 4STAR's direct irradiance measurement was dependent on the instrument

915 head temperature, which had to be corrected. This impact was up to $0.15 \% /{ }^{\circ} \mathrm{C}$ in transmittance. This was caused by the thermal expansion of the metal ferrule at the end of the fiber optic assembly pressing against the Spectralon diffusing element at the base of the light collecting Gershun tube. Spacing between the fiber optic bundle face and the Spectralon diffuser was adjusted, and mechanically stabilized to prevent temperature-dependent pistoning of the 920 connector from encroaching onto the diffuser.

Through cycling the head temperature in lab settings, the temperature dependence of the improved light path has been identified to vary less than $0.004 \% /{ }^{\circ} \mathrm{C}$, which is roughly equivalent to the worst-case scenario of optical depth changes of less than 0.004 with the sun directly at zenith, for temperatures ranging from $+50^{\circ} \mathrm{C}$ to $-50^{\circ} \mathrm{C}$. Typically the error in optical depth due to 925 the temperature variation was about 0.002 , due to the sun angle being on average much lower than zenith, and the majority of the temperature ranged to about half of the extremes.

\section{A.1.3 AOD window deposition correction}

930 During KORUS-AQ, 4STAR was subjected to varying thermal and atmospheric conditions and polluted atmospheres. During the science flights of the DC-8, the 4STAR window exposed to ambient air at the top of the DC- 8 became coated by a persistent thin contamination film that 
resulted in a reduction in the transmission efficiency of the window for potentially the remainder of the flight, until the window surface was cleaned when 4STAR was back on the ground. Table A1 showcases the impact of window deposition as measured on the ground post-flights by measuring the change in signal from a stable light source before versus after cleaning the window, with missing elements representing negligible (less than 1\%) impact. For 14 out the total 25 flights (research + check + transit flights), the amplitude difference was less than $2 \%$.

\begin{tabular}{|c|c|c|}
\hline Date & \begin{tabular}{|l|} 
Flight \\
number
\end{tabular} & \begin{tabular}{|l} 
Difference \\
[\%]
\end{tabular} \\
\hline 20160418 & PCF1 & - \\
\hline 20160421 & PCF2 & - \\
\hline 20160426 & TR1 & - \\
\hline 20160427 & TR2 & 1.28 \\
\hline 20160501 & 1 & 1.11 \\
\hline 20160503 & 2 & - \\
\hline 20160504 & 3 & - \\
\hline 20160506 & 4 & 2.80 \\
\hline 20160510 & 5 & - \\
\hline 20160511 & 6 & 6.22 \\
\hline 20160512 & 7 & 1.21 \\
\hline 20160516 & 8 & 6.88 \\
\hline 20160517 & 9 & 1.62 \\
\hline 20160519 & 10 & - \\
\hline 20160521 & 11 & 3.41 \\
\hline 20160524 & 12 & 36.00 \\
\hline 20160526 & 13 & 1.79 \\
\hline 20160529 & 14 & 10.11 \\
\hline 20160530 & 15 & 18.56 \\
\hline 20160601 & 16 & 19.33 \\
\hline 20160602 & 17 & 8.35 \\
\hline 20160604 & 18 & 16.09 \\
\hline 20160608 & 19 & 18.72 \\
\hline 20160609 & 20 & 22.09 \\
\hline 20160614 & tr3 & \\
\hline
\end{tabular}

940 Table A1 - Magnitude of light intensity change due to cleaning 4STAR's window post-flight, for the highest magnitude peak of the LED light source near $650 \mathrm{~nm}$ wavelength. Research flights are numbered, while project check flights and transit flights are indicated by acronyms PCF and TR, respectively.

945 To correct for window deposition on the AOD, each flight with greater than $2 \%$ post-flight light intensity difference is manually inspected to determine the set of discrete events leading to the 
deposition, notably during low-level near-water flight segments, in highly polluted periods, or during cloud insertions. The uncertainty in the AOD surrounding these events (within \pm 6 min) has been increased to the magnitude of the optical depth of the window deposition and by $30 \%$ of the corrected magnitude for the rest of the flight, producing a step-change in the AOD uncertainty. High altitude flight segments (above $6 \mathrm{~km}$ ) are used to evaluate the change in optical depth due to window deposition, where the AOD is expected to be mostly representative of the stratospheric aerosol, at around 0.03 . Fortunately, the typical flight maneuvers required profiling through the boundary layer and up to higher altitudes, frequently, enabling a 'bookend' check on the window deposition, confirming a reasonable correction. Figure A2 presents the impact of the window deposition correction on the AOD at $501 \mathrm{~nm}$ for all the flights during KORUS-AQ, as a function of altitude. A near constant vs. altitude impact is shown here of up to 0.1 , while the AOD vertical dependence is not highly impacted.

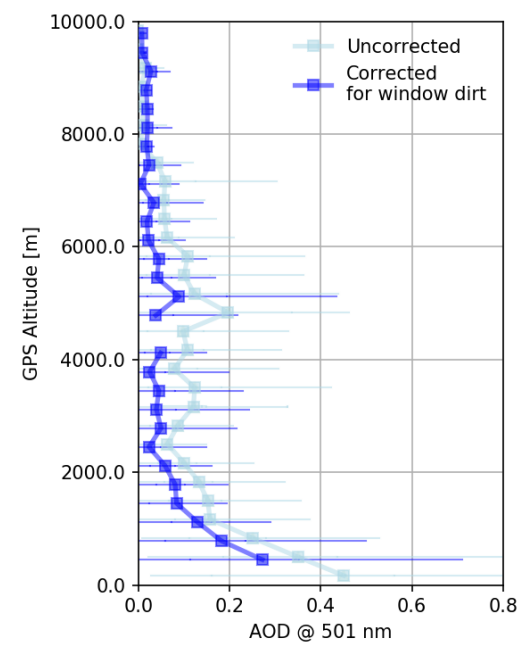

960 Figure A2 - Summary of the impact on correcting the AOD at $501 \mathrm{~nm}$ for window deposition during KORUS-AQ, as a function of altitude. The AOD is binned in roughly $200 \mathrm{~m}$ altitudes, with the error bars representing the interquartile range for each of those bins. 


\section{Appendix B: AOD comparisons}

\section{B.1 4STAR-GOCI AOD comparison}
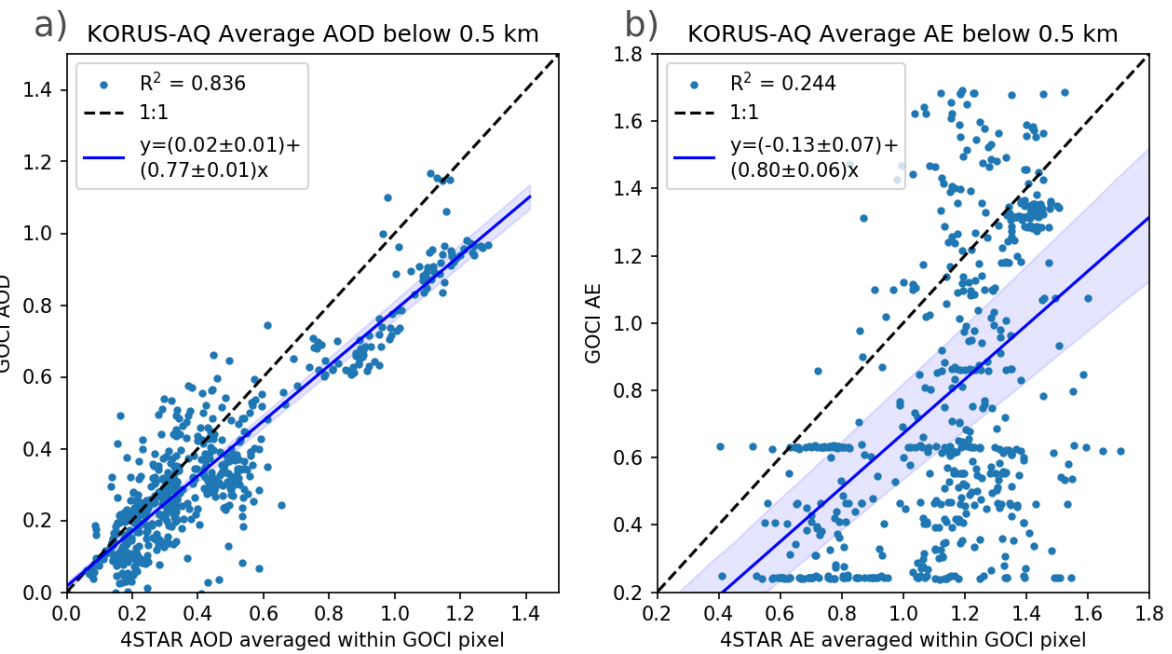

C)

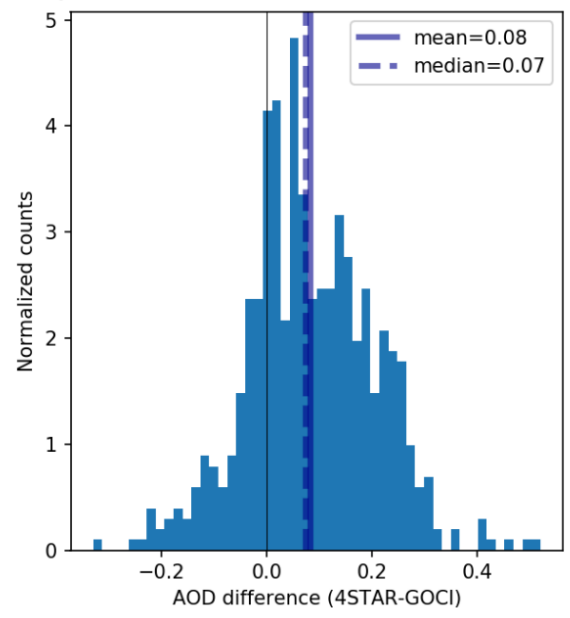

d)

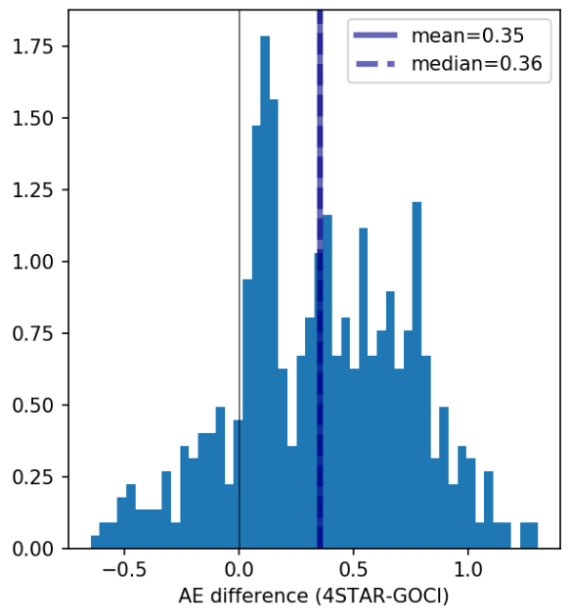

Figure B1 - Comparison of AOD at $500 \mathrm{~nm}$ from GOCl retrievals as compared to 4STAR measurements below $500 \mathrm{~m}$. For each cloud cleared GOCI pixel, the nearby 4STAR samples (within 30 minutes of $\mathrm{GOCl}$ retrievals) are averaged together for this comparison, shown in the upper pair of graphs ( $a$ for $A O D$ and $b$ for $A E$ ). The difference between the matched 4STAR to $\mathrm{GOCl}$ values are presented in the bottom pair of histograms (c for AOD and $d$ for $A E$ ). 
a) KORUS-AQ Average Fine mode AOD

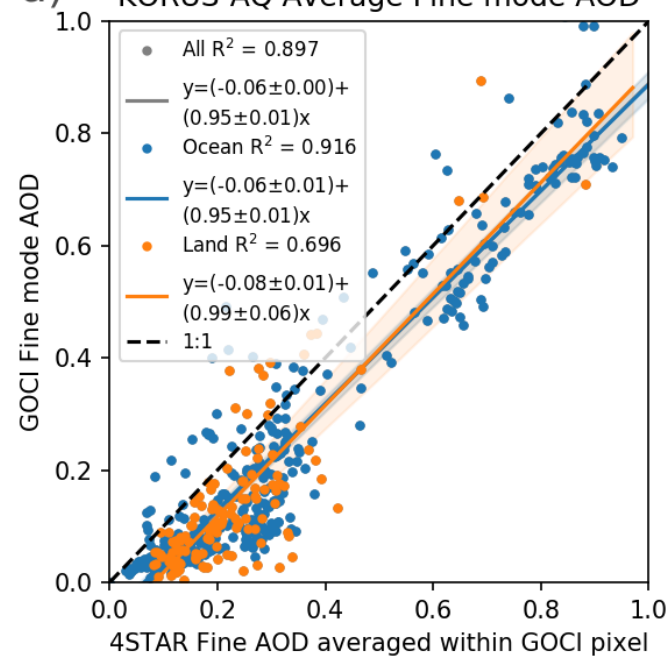

C)

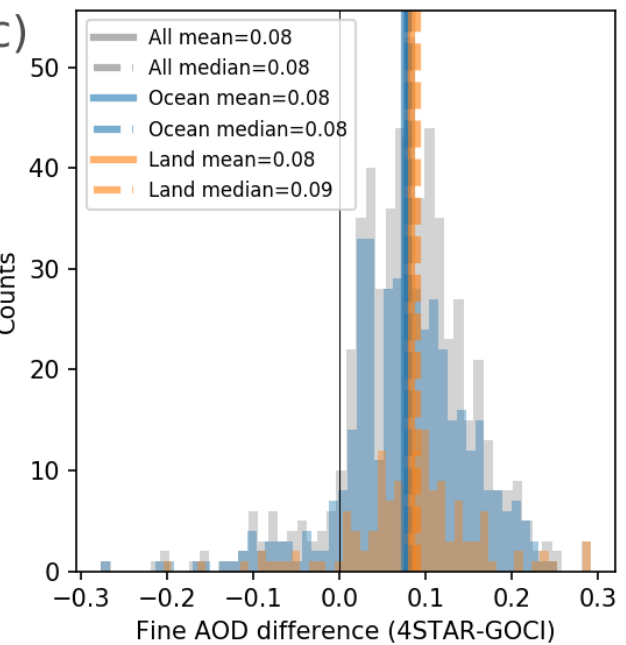

b) KORUS-AQ Average Coarse mode AOD

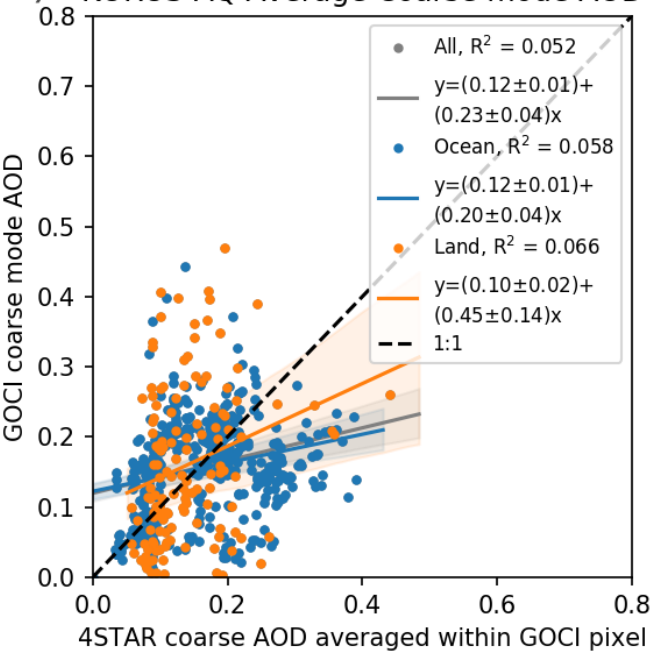

d)

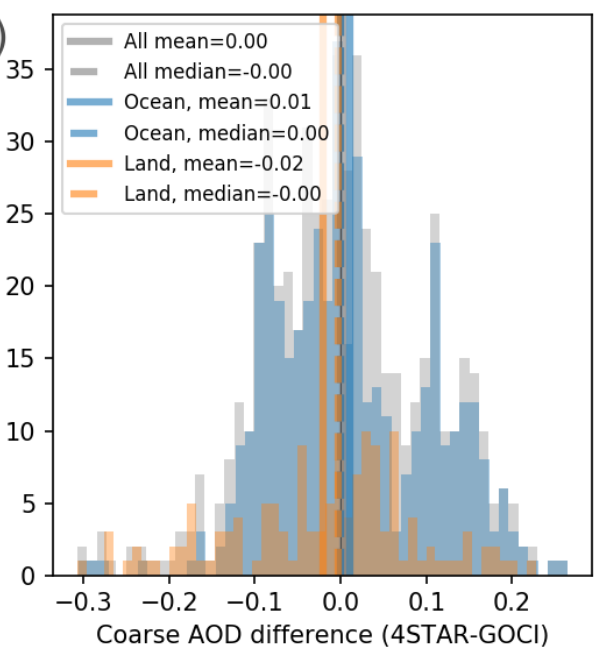

Figure B2 - Average 4STAR (a) fine and (b) coarse mode AOD within the different GOCI pixels matched on the same observation times and locations for all measurements under $500 \mathrm{~m}$. The differences between the observations by 4STAR and GOCI is found for fine mode AOD in (c) and for coarse mode AOD in (d). This comparison is subset between AOD measured over land (in orange) and over the ocean (in blue). The separation between land and ocean was achieved using the 1-km resolution GLOBE data (Hastings and Dunbar, 1999) ported for use in python (Karin, 2020). 


\section{B.2 4STAR-MERRA-2 AOD comparison}

Average aerosol below $0.5 \mathrm{~km}$ during KORUS-AQ (May-June 2016)
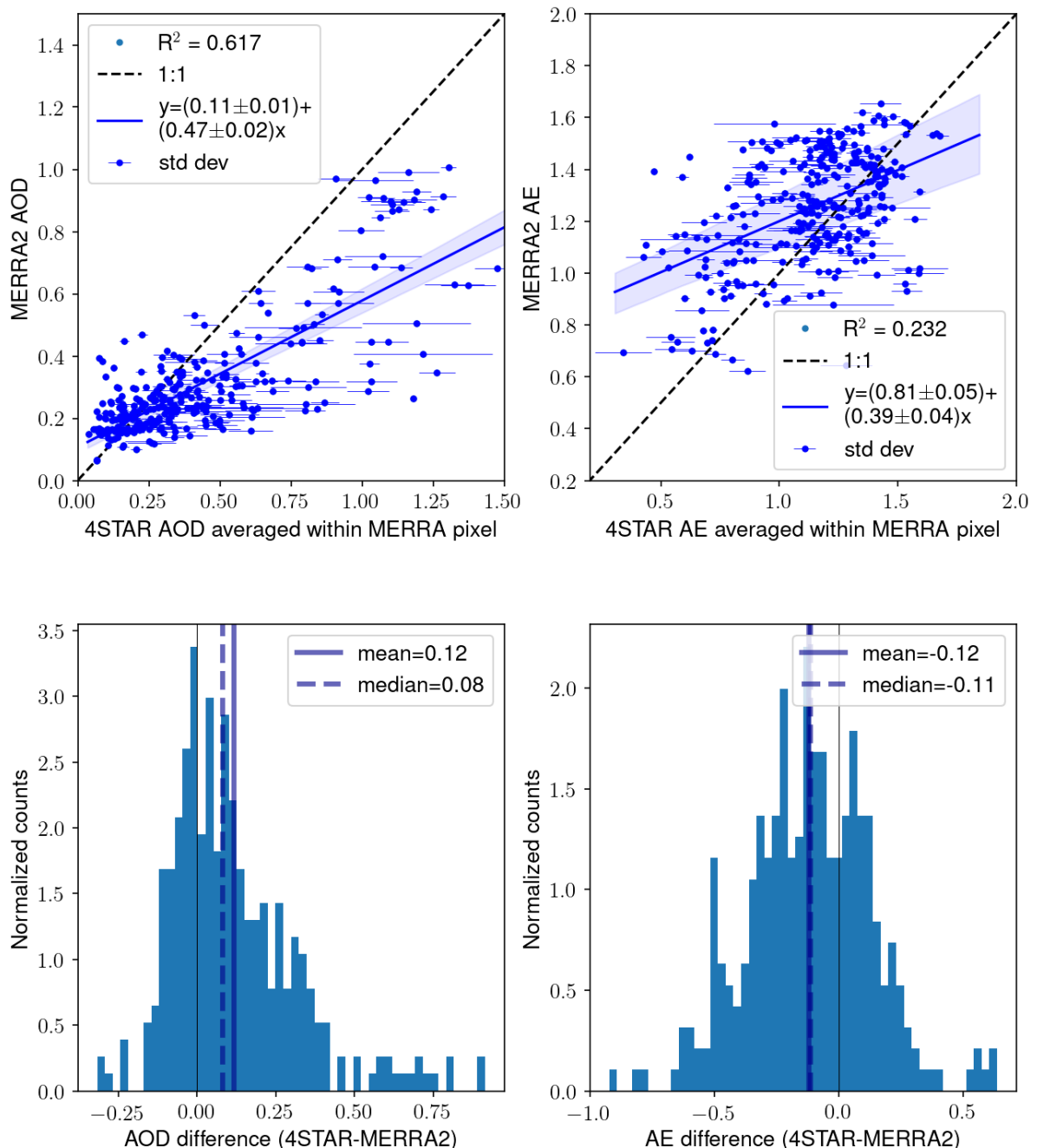

Figure B3 - Comparison of the AOD analysis from MERRA-2 as compared to 4STAR

measurements below $500 \mathrm{~m}$. For each pixel from MERRA-2 (at 3 hourly time steps), the nearby 4STAR samples (within 90 minutes of MERRA-2 run) are averaged together for this comparison, with the standard deviation of measured 4STAR AOD within one MERRA-2 pixel represented by the error bars, shown in the top pair of graphs. The difference between AOD and AE from 4STAR and MERRA-2 are shown by the bottom pair of histograms. 
990 Data Availability: Data for KORUS-AQ is available at the NASA LaRC data archive: https://www-air.larc.nasa.gov/cgi-bin/ArcView/korusaq, following the DOI: 10.5067/Suborbital/KORUSAQ/DATA01.

Author Contributions: SEL conceived the study, completed the analysis, and wrote the manuscript. SEL, MSR, JR, CF, collected data and operated 4STAR during KORUS-AQ. SEL, RRJ, SD, and RD worked on technical upgrades to 4STAR. JK, MC created and curated the GOCI AOD products (while MC was at Yonsei). LZ and KLT operated and produced the LARGE products. AD, PC, and QT advised on the use of MERRA-2 aerosol products with AD and PC contributing the 4-D MERRA-2 interpolated data. JR and MK secured ongoing support. All co-authors contributed to edits of the manuscript.

Competing Interests: The authors declare that they have no conflict of interest.

Acknowledgements: NASA DC-8 flight and maintaining staff along with ESPO are thanked for their essential contributions for successful KORUS-AQ deployment. Data collection by John Livingston (retired) is appreciated. NASA Atmospheric Composition Program (ACP) is acknowledged for their ongoing support. GOCI data was provided through "Technology development for Practical Applications of Multi-Satellite data to maritime issues" project of the Ministry of Ocean and Fisheries, Korea. 


\section{References}

4STAR Team, LeBlanc, S., Flynn, C. J., Pistone, K., Segal-Rozenhaimer, M., Kacenelenbogen, M. and Broccardo, S.: samuelleblanc/4STAR_codes: 4STAR processing codes for 2020, Zenodo, https://doi.org/10.5281/zenodo.3785745, 2020.

Anderson, T. L., Charlson, R. J., Winker, D. M., Ogren, J. A. and Holmén, K.: Mesoscale variations of tropospheric aerosols*, J. Atmos. Sci., 60(1), 119-136, https://doi.org/10.1175/1520-0469(2003)060<0119:MVOTA>2.0.CO;2, 2003.

1015 Buchard, V., Randles, C. A., da Silva, A. M., Darmenov, A., Colarco, P. R., Govindaraju, R., Ferrare, R., Hair, J., Beyersdorf, A. J., Ziemba, L. D. and Yu, H.: The MERRA-2 Aerosol Reanalysis, 1980 Onward. Part II: Evaluation and Case Studies, J. Clim., 30(17), 6851-6872, https://doi.org/10.1175/JCLI-D-16-0613.1, 2017.

Choi, M., Kim, J., Lee, J., Kim, M., Park, Y. J., Jeong, U., Kim, W., Hong, H., Holben, B., Eck, T. F., Song, C. H., Lim, J. H., and Song, C. K.: GOCI Yonsei Aerosol Retrieval (YAER) algorithm and validation during the DRAGON-NE Asia 2012 campaign. Atmospheric Measurement Techniques. https://doi.org/10.5194/amt-9-1377-2016, 2016.

Choi, J., Park, R. J., Lee, H.-M., Lee, S., Jo, D. S., Jeong, J. I., Henze, D. K., Woo, J.-H., Ban, S.-J., Lee, M.-D., Lim, C.-S., Park, M.-K., Shin, H. J., Cho, S., Peterson, D. and Song, C.-K.: Impacts of local vs. trans-boundary emissions from different sectors on PM2.5 exposure in South Korea during the KORUS-AQ campaign, Atmos. Environ., 203, 196-205, https://doi.org/10.1016/j.atmosenv.2019.02.008, 2019.

Choi, M., Kim, J., Lee, J., Kim, M., Park, Y.-J., Holben, B., Eck, T. F., Li, Z. and Song, C. H.: GOCI Yonsei aerosol retrieval version 2 products: an improved algorithm and error analysis with uncertainty estimation from 5-year validation over East Asia, Atmos. Meas. Tech., 11(1), 385408, https://doi.org/10.5194/amt-11-385-2018, 2018.

Choi, M., Lim, H., Kim, J., Lee, S., Eck, T. F., Holben, B. N., Liu, H.: Validation, comparison, and integration of GOCI, AHI, MODIS, MISR, and VIIRS aerosol optical depth over East Asia during the 2016 KORUS-AQ campaign. Atmospheric Measurement Techniques, 12(8), 4619-4641. https://doi.org/10.5194/amt-12-4619-2019, 2019.

Choi, Y. and Ghim, Y. S.: Variations in major aerosol components from long-term measurement of columnar aerosol optical properties at a SKYNET site downwind of Seoul, Korea, Atmos.

Environ., 245, 117991, https://doi.org/10.1016/j.atmosenv.2020.117991, 2021.

Choi, Y., Ghim, Y. S., Rozenhaimer, M. S., Redemann, J., LeBlanc, S. E., Flynn, C. J., Johnson, 1040 R. J., Lee, Y., Lee, T., Park, T., Schwarz, J. P., Lamb, K. D. and Perring, A. E.: Temporal and spatial variations of aerosol optical properties over the Korean peninsula during KORUS-AQ, Atmos. Environ., 118301, https://doi.org/10.1016/j.atmosenv.2021.118301, 2021.

Collow, A., Lucchesi, R., and Da Silva, A.: File Specification for GEOS Products Sampled Along Aircraft Trajectories. GMAO Office Note No. 18 (Version 1.0), 36 pp, available from

1045 http://gmao.gsfc.nasa.gov/pubs/office_notes, 2020.

Crawford, J. H., Ahn, J.-Y., Al-Saadi, J., Chang, L., Emmons, L. K., Kim, J., Lee, G., Park, J.-H., Park, R. J., Woo, J. H., Song, C.-K., Hong, J.-H., Hong, Y.-D., Lefer, B. L., Lee, M., Lee, T., 
Kim, S., Min, K.-E., Yum, S. S., Shin, H. J., Kim, Y.-W., Choi, J.-S., Park, J.-S., Szykman, J. J., Long, R. W., Jordan, C. E., Simpson, I. J., Fried, A., Dibb, J. E., Cho, S. and Kim, Y. P.: The doi:10.1525/elementa.2020.00163, 2021.

Dunagan, S., Johnson, R., Zavaleta, J., Russell, P., Schmid, B., Flynn, C., Redemann, J., Shinozuka, Y., Livingston, J. and Segal-Rosenhaimer, M.: Spectrometer for Sky-Scanning SunTracking Atmospheric Research (4STAR): Instrument Technology, Remote Sens (Basel), 5(8), 3872-3895, https://doi.org/10.3390/rs5083872, 2013.

Eck, T.F., Holben, B.N., Reid, J.S., Dubovik, O., Smirnov, A., O'Neill, N.T., Slutsker, I., and Kinne, S.: Wavelength dependence of the optical depth of biomass burning, urban, and desert dust aerosols. J. Geophys. Res. 104, 31333-31349, 1999.

Eck, T. F., Holben, B. N., Sinyuk, A., Pinker, R. T., Goloub, P., Chen, H., Chatenet, B., Li, Z., 1060 Singh, R. P., Tripathi, S. N., Reid, J. S., Giles, D. M., Dubovik, O., O’Neill, N. T., Smirnov, A., Wang, P. and Xia, X.: Climatological aspects of the optical properties of fine/coarse mode aerosol mixtures, J. Geophys. Res. Atmos., 115(19), 1-20, doi:10.1029/2010JD014002, 2010.

Eck, T. F., Holben, B. N., Kim, J., Beyersdorf, A. J., Choi, M., Lee, S., Koo, J. H., Giles, D. M., Schafer, J. S., Sinyuk, A., Peterson, D. A., Reid, J. S., Arola, A., Slutsker, I., Smirnov, A.,

1065 Sorokin, M., Kraft, J., Crawford, J. H., Anderson, B. E., Thornhill, K. L. and Park, S.: Influence of cloud, fog, and high relative humidity during pollution transport events in South Korea: Aerosol properties and PM2.5 variability, Atmos. Environ., 117530, https://doi.org/10.1016/j.atmosenv.2020.117530, 2020.

Global Modeling And Assimilation Office: MERRA-2 tavg1_2d_aer_Nx: 2d,1-Hourly,Time1070 averaged,Single-Level,Assimilation,Aerosol Diagnostics V5.12.4, NASA Goddard Earth Sciences Data and Information Services Center, Greenbelt, MD, USA(Goddard Earth Sciences Data and Information Services Center (GES DISC)), Accessed: 2020-09-17, https://doi.org/10.5067/klicltz8em9d, 2015.

Gong, S. L.: A parameterization of sea-salt aerosol source function for sub- and super-micron 1075 particles, Global Biogeochemical Cycles, vol. 17, no. 4, Oct. 2003.

Gong, S. L., Barrie, L. A., and Blanchet, J. P.: Modeling sea-salt aerosols in the atmosphere: 1. Model development, J. Geophys. Res. Atmos., vol. 102, no. 3, pp. 3805-3818, Feb. 1997.

Hastings, David A., and Paula K. Dunbar: Global Land One-kilometer Base Elevation (GLOBE) Digital Elevation Model, Documentation, Volume 1.0. Key to Geophysical Records

1080 Documentation (KGRD) 34. National Oceanic and Atmospheric Administration, National Geophysical Data Center, 325 Broadway, Boulder, Colorado 80303, U.S.A., 1999

Heim, E. W., Dibb, J., Scheuer, E., Jost, P. C., Nault, B. A., Jimenez, J. L., Peterson, D., Knote, C., Fenn, M., Hair, J., Beyersdorf, A. J., Corr, C. and Anderson, B. E.: Asian dust observed during KORUS-AQ facilitates the uptake and incorporation of soluble pollutants during transport to South Korea, Atmos. Environ., 224, 117305, https://doi.org/10.1016/j.atmosenv.2020.117305, 2020.

Hodzic, A., Kasibhatla, P. S., Jo, D. S., Cappa, C. D., Jimenez, J. L., Madronich, S. and Park, R. 
J.: Rethinking the global secondary organic aerosol (SOA) budget: Stronger production, faster removal, shorter lifetime, Atmos. Chem. Phys., 16(12), 7917-7941, doi:10.5194/acp-16-79172016, 2016.

Holben, B. N., Eck, T. F., Slutsker, I., Tanré, D., Buis, J. P., Setzer, A., Vermote, E., Reagan, J. A., Kaufman, Y. J., Nakajima, T., Lavenu, F., Jankowiak, I. and Smirnov, A.: AERONET-A federated instrument network and data archive for aerosol characterization, Remote Sensing of Environment, 66(1), 1-16, https://doi.org/10.1016/S0034-4257(98)00031-5, 1998.

1095 Hou, W., Wang, J., Xu, X., Reid, J. S., Janz, S. J. and Leitch, J. W.: An algorithm for hyperspectral remote sensing of aerosols: 3. Application to the GEO-TASO data in KORUS-AQ field campaign, Journal of Quantitative Spectroscopy and Radiative Transfer, 253, 107161, https://doi.org/10.1016/j.jqsrt.2020.107161, 2020.

Jordan, C. E., Crawford, J. H., Beyersdorf, A. J., Eck, T. F., Halliday, H. S., Nault, B. A., Chang, 1100 L.-S., Park, J., Park, R., Lee, G., Kim, H., Ahn, J.-Y., Cho, S., Shin, H. J., Lee, J. H., Jung, J., Kim, D.-S., Lee, M., Lee, T., Whitehill, A. and Schwarz, J. P.: Investigation of factors controlling PM2.5 variability across the South Korean Peninsula during KORUS-AQ., Elementa (Wash D C), 8(28), https://doi.org/10.1525/elementa.424, 2020.

Todd Karin: toddkarin/global-land-mask: Release of version 1.0.0, 1105 https://doi.org/10.5281/zenodo.4066722, 5 October 2020.

Kaku, K. C., Reid, J. S., Hand, J. L., Edgerton, E. S., Holben, B. N., Zhang, J. and Holz, R. E.: Assessing the Challenges of Surface-Level Aerosol Mass Estimates From Remote Sensing During the SEAC4RS and SEARCH Campaigns: Baseline Surface Observations and Remote Sensing in the Southeastern United States, J. Geophys. Res. Atmos., 123(14), 7530-7562, 1110 doi:10.1029/2017JD028074, 2018.

Köpke, P., M. Hess, I. Schult, and E. P. Shettle, Global aerosol data set, report, Max-Planck Inst. für Meteorol., Hamburg, Germany, 243, 44 pp., 1997.

Koo, J. H., Lee, J., Kim, J., Eck, T. F., Giles, D. M., Holben, B. N., Park, S. S., Choi, M., Kim, N., Yoon, J. and Lee, Y. G.: Investigation of the relationship between the fine mode fraction and

1115 Ångström exponent: Cases in Korea, Atmos. Res., 248(March 2020), 105217, doi:10.1016/j.atmosres.2020.105217, 2021.

LeBlanc, S. E., Redemann, J., Flynn, C., Pistone, K., Kacenelenbogen, M., Segal-Rosenheimer, M., Shinozuka, Y., Dunagan, S., Dahlgren, R. P., Meyer, K., Podolske, J., Howell, S. G., Freitag, S., Small-Griswold, J., Holben, B., Diamond, M., Wood, R., Formenti, P., Piketh, S., Maggs-

1120 Kölling, G. and Namwoonde, A.: Above-cloud aerosol optical depth from airborne observations in the southeast Atlantic, Atmospheric Chemistry and Physics, 20(3), 1565-1590, https://doi.org/10.5194/acp-20-1565-2020, 2020.

Lee, S., Hong, J., Cho, Y., Choi, M., Kim, J., Park, S. S., Ahn, J. Y., Kim, S. K., Moon, K. J., Eck, T. F., Holben, B. N. and Koo, J. H.: Characteristics of classified aerosol types in South 1125 Korea during the MAPS-Seoul campaign, Aerosol Air Qual. Res., 18(9), 2195-2206, doi:10.4209/aaqr.2017.11.0474, 2018.

Lee, S., Kim, J., Choi, M., Hong, J., Lim, H., Eck, T. F., Holben, B. N., Ahn, J.-Y., Kim, J., and 
Koo, J.-H.: Analysis of long-range transboundary transport (LRTT) effect on Korean aerosol pollution during the KORUS-AQ campaign. Atmospheric Environment, 204(September 2018), 53-67. https://doi.org/10.1016/j.atmosenv.2019.02.020, 2019.

Li, L., Che, H., Derimian, Y., Dubovik, O., Schuster, G. L., Chen, C., Li, Q., Wang, Y., Guo, B. and Zhang, X.: Retrievals of fine mode light-absorbing carbonaceous aerosols from POLDER/PARASOL observations over East and South Asia, Remote Sensing of Environment, 247, 111913, https://doi.org/10.1016/j.rse.2020.111913, 2020.

1135 Liu, Q, Jia, X, Quan, J, Li, J, Li, X, Wu, Y, Chen, D, Wang, Z and Liu, Y.: New positive feedback mechanism between boundary layer meteorology and secondary aerosol formation during severe haze events. Scientific Reports 8. DOI: https://doi. org/10.1038/s41598-018-24366-3, 2018.

McNaughton, C. S., Clarke, A. D., Howell, S. G., Pinkerton, M., Anderson, B., Thornhill, L., 1140 Hudgins, C., Winstead, E., Dibb, J. E., Scheuer, E. and Maring, H.: Results from the DC-8 Inlet Characterization Experiment (DICE): Airborne Versus Surface Sampling of Mineral Dust and Sea Salt Aerosols, Aerosol Science and Technology, 41(2), 136-159, https://doi.org/10.1080/02786820601118406, 2007.

O'Neill, N. T.: Spectral discrimination of coarse and fine mode optical depth, J. Geophys. Res., 1145 108(D17), 4559, https://doi.org/10.1029/2002JD002975, 2003.

O’Neill, N. T., Eck, T. F., Holben, B. N., Smirnov, A., Dubovik, O. and Royer, A.: Bimodal size distribution influences on the variation of Angstrom derivatives in spectral and optical depth space, J. Geophys. Res., 106(D9), 9787-9806, https://doi.org/10.1029/2000JD900245, 2001a.

O'Neill, N. T., Dubovik, O. and Eck, T. F.: Modified angström exponent for the characterization

1150 of submicrometer aerosols., Appl. Opt., 40(15), 2368-2375, https://doi.org/10.1364/ao.40.002368, 2001b.

O'Neill, N. T., Eck, T., Smirnov, A., Holben, B. and Thulasiraman, S.: Spectral deconvolution algorithm technical memo, version 4.1., NASA Goddard Space Flight Center https://aeronet.gsfc.nasa.gov/new_web/PDF/tauf_tauc_technical_memo1.pdf, last access: 31

1155 March 2020, 2008.

Park, M., Yum, S. S., Kim, N., Anderson, B. E., Beyersdorf, A. and Thornhill, K. L.: On the submicron aerosol distributions and CCN activity in and around the Korean Peninsula measured onboard the NASA DC-8 research aircraft during the KORUS-AQ field campaign, Atmos. Res., 243, 105004, https://doi.org/10.1016/j.atmosres.2020.105004, 2020a.

1160 Park, S. S., Kim, S. W., Song, C. K., Park, J. U. and Bae, K. H.: Spatio-temporal variability of aerosol optical depth, total ozone and NO2 Over East Asia: Strategy for the validation to the GEMS scientific products, Remote Sens., 12(14), doi:10.3390/rs12142256, $2020 \mathrm{~b}$.

Peterson, D. A., Hyer, E. J., Han, S.-O., Crawford, J. H., Park, R. J., Holz, R., Kuehn, R. E., Eloranta, E., Knote, C., Jordan, C. E. and Lefer, B. L.: Meteorology influencing springtime air 1165 quality, pollution transport, and visibility in Korea, Elem Sci Anth, 7(1), 57, https://doi.org/10.1525/elementa.395, 2019.

Pistone, K., Redemann, J., Doherty, S., Zuidema, P., Burton, S., Cairns, B., Cochrane, S., 
Ferrare, R., Flynn, C., Freitag, S., Howell, S. G., Kacenelenbogen, M., LeBlanc, S., Liu, X., Schmidt, K. S., III, A. J. S., Segal-Rozenhaimer, M., Shinozuka, Y., Stamnes, S., van Diedenhoven, B., Van Harten, G. and Xu, F.: Intercomparison of biomass burning aerosol optical properties from in situ and remote-sensing instruments in ORACLES-2016, Atmos. Chem. Phys., 19, 9181-9208, doi:10.5194/acp-19-9181-2019, 2019.

Rajesh, T. A. and Ramachandran, S.: Extensive and intensive properties of aerosol over distinct environments: Influence of anthropogenic emissions and meteorology, Journal of Atmospheric and Solar-Terrestrial Physics, 202, 105223, https://doi.org/10.1016/j.jastp.2020.105223, 2020.

Randles, C. A., da Silva, A. M., Buchard, V., Colarco, P. R., Darmenov, A., Govindaraju, R., Smirnov, A., Holben, B., Ferrare, R., Hair, J., Shinozuka, Y. and Flynn, C. J.: The MERRA-2 Aerosol Reanalysis, 1980 Onward. Part I: System Description and Data Assimilation Evaluation, J. Clim., 30(17), 6823-6850, https://doi.org/10.1175/JCLI-D-16-0609.1, 2017.

1180 Redemann, J., Zhang, Q., Schmid, B., Russell, P. B., Livingston, J. M., Jonsson, H. and Remer, L. A.: Assessment of MODIS-derived visible and near-IR aerosol optical properties and their spatial variability in the presence of mineral dust, Geophys. Res. Lett., 33(18), https://doi.org/10.1029/2006GL026626, 2006.

Russell, P. B., Bergstrom, R. W., Shinozuka, Y., Clarke, a D., DeCarlo, P. F., Jimenez, J. L., 1185 Livingston, J. M., Redemann, J., Dubovik, O. and Strawa, A.: Absorption Angstrom Exponent in AERONET and related data as an indicator of aerosol composition, Atmos. Chem. Phys., 10(3), 1155-1169, 2010.

Saide, P. E., Gao, M., Lu, Z., Goldberg, D. L., Streets, D. G., Woo, J.-H., Beyersdorf, A., Corr, C. A., Thornhill, K. L., Anderson, B., Hair, J. W., Nehrir, A. R., Diskin, G. S., Jimenez, J. L.,

1190 Nault, B. A., Campuzano-Jost, P., Dibb, J., Heim, E., Lamb, K. D., Schwarz, J. P. and Crawford, J. H.: Understanding and improving model representation of aerosol optical properties for a Chinese haze event measured during KORUS-AQ, Atmospheric Chemistry and Physics, 20(11), 6455-6478, https://doi.org/10.5194/acp-20-6455-2020, 2020.

Sayer, A. M.: How long is too long? variogram analysis of AERONET data to aid aerosol 1195 validation and intercomparison studies, Earth and Space Science, 7(9), https://doi.org/10.1029/2020EA001290, 2020.

Schuster, G. L., Dubovik, O., and Holben, B. N.: Angstrom exponent and bimodal aerosol size distributions, J. Geophys. Res., 111, D07207, 10.1029/2005jd006328, 2006.

Segal-Rosenheimer, M., Russell, P. B., Schmid, B., Redemann, J., Livingston, J. M., Flynn, C. 1200 J., Johnson, R. R., Dunagan, S. E., Shinozuka, Y., Herman, J. R., Cede, A., Abuhassan, N., Comstock, J. M., Hubbe, J. M., Zelenyuk, A. and Wilson, J.: Tracking elevated pollution layers with a newly developed hyperspectral Sun/Sky spectrometer (4STAR): Results from the TCAP 2012 and 2013 campaigns, J. Geophys. Res. Atmos., 119, 1-18, doi:10.1002/2013JD020884.Received, 2014.

1205 Shinozuka, Y. and Redemann, J.: Horizontal variability of aerosol optical depth observed during the ARCTAS airborne experiment, Atmospheric Chemistry and Physics, 11(16), 8489-8495, https://doi.org/10.5194/acp-11-8489-2011, 2011. 
Shinozuka, Y., Johnson, R. R., Flynn, C. J., Russell, P. B., Schmid, B., Redemann, J., Dunagan, S. E., Kluzek, C. D., Hubbe, J. M., Segal-Rosenheimer, M., Livingston, J. M., Eck, T. F., Wagener, R., Gregory, L., Chand, D., Berg, L. K., Rogers, R. R., Ferrare, R. A., Hair, J. W., Hostetler, C. A. and Burton, S. P.: Hyperspectral aerosol optical depths from TCAP flights, J. Geophys. Res. Atmos., 118(21), 12,180-12,194, https://doi.org/10.1002/2013JD020596, 2013.

Shin, S. K., Müller, D., Lee, C., Lee, K. H., Shin, D., Kim, Y. J. and Noh, Y. M.: Vertical variation of optical properties of mixed Asian dust/pollution plumes according to pathway of air mass transport over East Asia, Atmospheric Chemistry and Physics, 15(12), 6707-6720, https://doi.org/10.5194/acp-15-6707-2015, 2015.

Targino, A. C., Noone, K. J. and Öström, E.: Airborne in situ characterization of dry aerosol optical properties in a multisource influenced marine region, Tellus B: Chemical and Physical Meteorology, 57(3), 247-260, https://doi.org/10.3402/tellusb.v57i3.16537, 2005.

1220 Tsigaridis, K., Daskalakis, N., Kanakidou, M., Adams, P. J., Artaxo, P., Bahadur, R., Balkanski, Y., Bauer, S. E., Bellouin, N., Benedetti, A., Bergman, T., Berntsen, T. K., Beukes, J. P., Bian, H., Carslaw, K. S., Chin, M., Curci, G., Diehl, T., Easter, R. C., Ghan, S. J., Gong, S. L., Hodzic, A., Hoyle, C. R., Iversen, T., Jathar, S., Jimenez, J. L., Kaiser, J. W., Kirkeväg, A., Koch, D., Kokkola, H., H Lee, Y., Lin, G., Liu, X., Luo, G., Ma, X., Mann, G. W., Mihalopoulos, N.,

1225 Morcrette, J. J., Müller, J. F., Myhre, G., Myriokefalitakis, S., Ng, N. L., O'donnell, D., Penner, J. E., Pozzoli, L., Pringle, K. J., Russell, L. M., Schulz, M., Sciare, J., Seland, Shindell, D. T., Sillman, S., Skeie, R. B., Spracklen, D., Stavrakou, T., Steenrod, S. D., Takemura, T., Tiitta, P., Tilmes, S., Tost, H., Van Noije, T., Van Zyl, P. G., Von Salzen, K., Yu, F., Wang, Z., Wang, Z., Zaveri, R. A., Zhang, H., Zhang, K., Zhang, Q. and Zhang, X.: The AeroCom evaluation and intercomparison of organic aerosol in global models, Atmos. Chem. Phys., 14(19), 1084510895, doi:10.5194/acp-14-10845-2014, 2014.

Virkkula, A.: Correction of the Calibration of the 3-wavelength Particle Soot Absorption Photometer (3ג PSAP), Aerosol Science and Technology, 44(8), 706-712, https://doi.org/10.1080/02786826.2010.482110, 2010.

1235 Yoon, J., von Hoyningen-Huene, W., Kokhanovsky, A. A., Vountas, M., and Burrows, J. P.: Trend analysis of aerosol opti- cal thickness and Ångström exponent derived from the global AERONET spectral observations, Atmos. Meas. Tech., 5, 1271-1299, https://doi.org/10.5194/amt-5-1271-2012, 2012.

Ziemba, L. D., Lee Thornhill, K., Ferrare, R., Barrick, J., Beyersdorf, A. J., Chen, G., 1240 Crumeyrolle, S. N., Hair, J., Hostetler, C., Hudgins, C., Obland, M., Rogers, R., Scarino, A. J., Winstead, E. L. and Anderson, B. E.: Airborne observations of aerosol extinction by in situ and remote-sensing techniques: Evaluation of particle hygroscopicity, Geophys. Res. Lett., 40(2), 417-422, https://doi.org/10.1029/2012GL054428, 2013. 